\title{
Winglet Effect on Hydrodynamic Performance and Trajectory of a
}

\section{Blended-wing-body Underwater Glider}

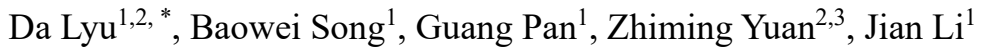 \\ ${ }^{1}$ School of Marine Science and Technology, Northwestern Polytechnical University, Xi'an, 710072, \\ China. \\ ${ }^{2}$ Department of Naval Architecture, Ocean \& Marine Engineering, University of Strathclyde, \\ Glasgow, G4 0LZ, United Kingdom. \\ ${ }^{3}$ School of Naval Architecture and Ocean Engineering, Jiangsu University of Science and \\ Technology, Zhenjiang, 212003, China. \\ * Corresponding author. Email: lyuda@mail.nwpu.edu.cn
}

\begin{abstract}
Winglet has been widely used in aviation industries to improve the performance of aircraft. However, according to the authors' knowledge, the effect of winglet on underwater gliders has not been investigated in detail. This paper aims to investigate the impact of winglet on hydrodynamic performance and gliding trajectory of a blended-wing-body underwater glider (BWBUG). The hydrodynamic performance of the BWBUG without winglet (BWBUG-I) is firstly calculated. Then the hydrodynamic performance of BWBUG with winglet (BWBUG-II) is analyzed and compared. To estimate the influence of winglet on gliding trajectory, a dynamic model is established by considering the buoyancy and pitch regulating system. From the CFD results, the lift force acting on the glider is increased by the winglet, while the drag force remains at the same level. The lift-todrag ratio is thereby improved. By comparing trajectories, the average gliding ratio for BWBUG-II is $5.10,2.2 \%$ higher than 4.99 for BWBUG-I. With the winglet, the extreme attack angle is reduced from $7.2^{\circ}$ to $6.1^{\circ}$ when switching from rising to diving. The steady gliding speed is improved by $6.3 \%$, and the squat depth is reduced by $11 \%$ under particular condition.
\end{abstract}

Keywords Underwater glider; Blended-wing-body; Winglet; Trajectory; Computational fluid dynamics; Buoyancy and pitch regulating system

\section{Introduction}

Autonomous Underwater Glider (AUG) is developed as a new kind of Unmanned Underwater Vehicles (UUV) during the past decades. Different to most tradition UUV, AUG drives itself by changing the buoyancy to move vertically and changes the attitude by moving the mass blocks inside to move forward with the help of hydrodynamic forces on wings. After the first conceptual design of underwater was proposed by Stommel, several types of underwater glider were designed and applied in various oceanographic research. Slocum, including thermal ones and electronical ones, have been deployed successfully in several missions (Webb et al., 2001). Woithe et al. (Woithe et al., 2010) discussed the power and energy management of Slocum glider predict energy consumption and endurance in a specific mission. Eichhorn et al. (Eichhorn, 2010) presented several requirements in optimizing the path based on practice research. The Spray glider (Sherman et al., 2001) was designed at Scripts Institution of Oceanography. It has been applied to observe the 
California Current System, explore the transport in the Solomon Sea, monitor the western boundary of North Atlantic and study the origin of the Kuroshio in terms of a glider fleet (Rudnick et al., 2010). Fu et al. (Fu et al., 2018) performed NSGA-II optimization to carry out an optimized shape which hydrodynamic performance has been improved when compared to the Spray glider. Seaglider, introduced by Eriksen et al. (Eriksen et al., 2001), has been applied to monitor whales near Hawaiian (Klinck et al., 2011). Eleanor et al. (Eleanor et al., 2011) estimated the vertical water velocity by Seaglider. Petrel, a hybrid power glider, is developed by Wang et al. (Wang et al., 2011) before applying to analyze the noise spectrogram of South China Sea. Yang et al. (Yang et al., 2017) studied the trajectory of Petrel-II by taking into consideration the deformation of the hulls and seawater density variation. The negative effect bring by the density variationwas reduced by a proposed buoyancy compensation scheme. The gliders mentioned above are examples of tradition underwater glider (TUG) composed by a cylindrical main body and one pair of flat wings on both sides.

To achieve higher fuel efficiency, the blended-wing-body technology has been developed for decades in aerospace industry before being applied in AUG design. Liebeck et al. (Liebeck et al., 1998) discussed the potential of BWB airplanes in undertaking subsonic transport. Moreno et al. (Ayuso Moreno et al., 2006) compared the BWB configuration with conventional ones and pointed out the superior hydrodynamic performance of BWB. For underwater gliders, researchers from ONR adopted the BWB layout firstly and carried out the Liberdade class underwater glider (D'Spain et al., 2005). Sun et al. (Sun et al., 2015) optimized the shape of a blended-wing-body underwater glider (BWBUG) to a longer sailing range and higher lift-to-drag ratio. He et al. (He et al., 2017) optimized the structures and the structural weight by $10.8 \%$. Wang et al. (Wang et al., 2015) developed a HFWUG and revealed the improvement in gliding efficiency of HFWUG. In summary, the BWB technology has a promising effect in improving the performance of underwater gliders. However, the BWBUG or HFWUG are currently without any vertical surface or tails, which lead to the newly designed glider lack of vertical steady surface. Which means the underwater glider has to spare energy for the inner devices in maintaining the gliding direction (Fan and Woolsey, 2014). This scenario has been considered as a constraint to extensive sailing range of underwater gliders.

The winglet, or ending plates, is widely used in aircraft industries to increase the aerodynamic performance of aircraft. As a result, aircraft with winglets are more energy-efficient than these without winglet. Riley (Riley, 1951) conducted a wind-tunnel investigation to study the effects of end plates on an un-swept wing. Results showed that the end plate helped to increase the lift-curve slop and reduced the induced drag. Takenaka et al. (Takenaka et al., 2008) carried out a multidisciplinary design for a winglet used by a commercial aircraft to improve the maximum takeoff weight. Jacob et al. (Weierman and Jacob, 2010) investigated the design and optimization for UAVs and revealed the effect of winglet on lift coefficient and drag coefficient. The optimized maximum lift-to-drag ratio increased by $28 \%$. Liebeck et al. (Liebeck et al., 1998) addressed the function of winglets as vertical surface to provide primary directional stability and control for tailless BWB configuration. In a previous study carried out by the authors, the drag reduction effect of winglet on BWBUG is studied, in which the winglet helped to reduce the drag coefficient by $13 \%$ under certain conditions. However, the influence of winglet on hydrodynamic performance and gliding trajectory is yet to be clarified.

In this paper, the influence of winglet on BWBUG is thoroughly studied by answering the following the questions: How much differences are there for BWBUG with and without winglet, in 
terms of hydrodynamic performance and trajectory? How the inner device affects the gliding trajectory? To answer the questions, a kinematics and dynamics model of a BWBUG is established. For conventional underwater vehicles, the mass is constant. However, for BWBUG, the mass and center of gravity are time-changing variables due to the adjustment of buoyancy and pitching regulating system (BPRS). Thus, the kinematics and dynamics model of BWBUG is established with the position adjusting of inner device considered and a framework to estimate the trajectory is proposed. Then the hydrodynamic performance of BWBUG with winglet (BWBUG-II) is calculated by commercial CFD software Fluent and compared with the hydrodynamic characters of BWBUG without winglet (BWBUG-I). Finally, the influence of winglet on hydrodynamic performance and trajectories is investigated.

\section{Mathematical model}

\subsection{Geometry model}

The BWBUG discussed in this paper has no clear boundary between the main body and wings. The shape of the leading edge and trailing edge are determined by the Bezier curve. The configuration design for BWBUG with and without winglet was finished previously and the drag reduction effect of single upper winglet on BWBUG was investigated (Lü et al., 2018). In this paper, the winglet configuration is adopted from the previous study. Fig. 1 shows the geometry model of BWBUG-I and BWBUG-II, where $L$ and $C_{t}$ represent the spanwise and chord length of BWBUG, respectively. In this paper $L=3 \mathrm{~m}, C_{t}=1.8 \mathrm{~m}$, and the average chord length $L_{c}=0.54 \mathrm{~m}$. The configuration of winglet is characterized by height $(h=0.1 L)$ and sweep angle $\left(\eta=30^{\circ}\right)$.

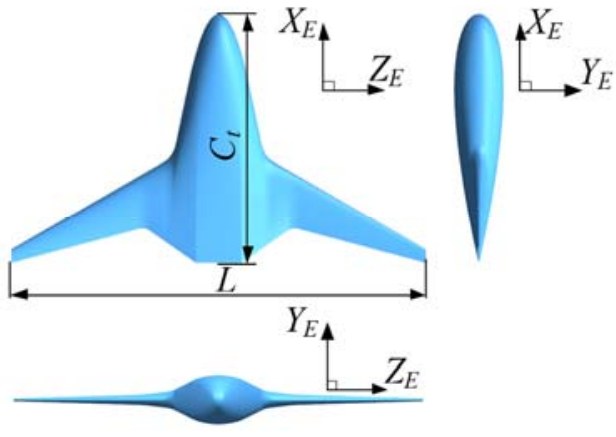

(a)

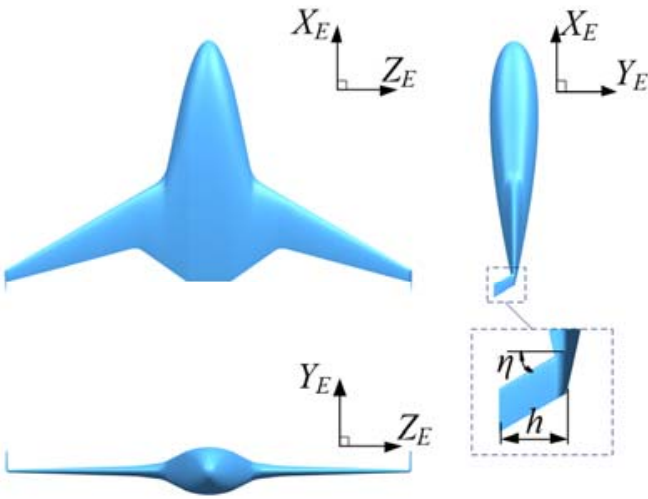

(b)

Fig. 1. Geometry models of BWBUG for (a) BWBUG-I without winglet and (b) BWBUG-II with winglet.

\subsection{Kinematics and dynamics model of BWBUG}

In this paper, the equations to describe the motion of the BWBUG is established within bodyfixed frame while the trajectory is expressed in the earth-fixed frame. The determination of the coordination systems is shown in Fig. 2. 


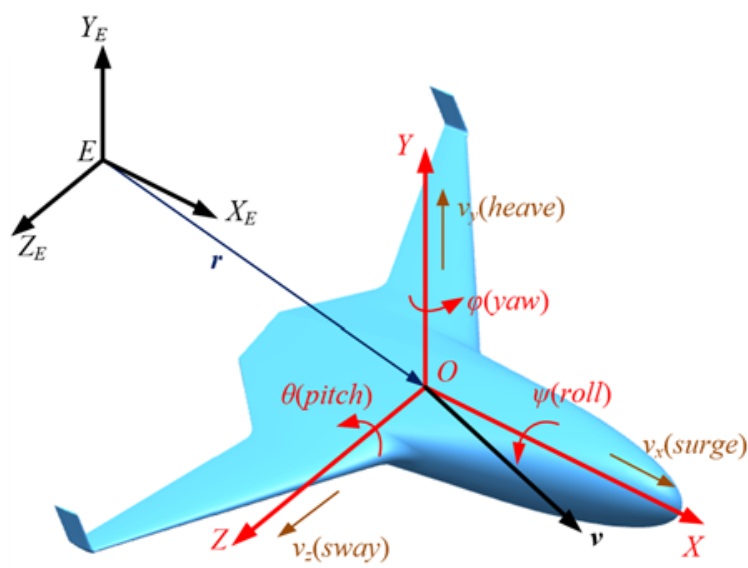

Fig. 2. Coordination systems for a BWBUG. $O-X Y Z$ represents the body-fixed frame, and $E-X_{E} Y_{E} Z_{E}$ represents the earth-fixed frame.

The forces act on BWBUG is composed by hydrodynamic forces, gravity and buoyancy. Moreover, the center of buoyancy $(\mathrm{CB})$ is different with center of gravity $(\mathrm{CG})$ so a moment is implied in addition to the net buoyancy. To carried out a dynamic model for BWBUG, the momentum theorem and the moment of momentum theorem are applied choosing $\mathrm{CG}$ as reference point,

$$
\begin{aligned}
& d \boldsymbol{Q} / d t=\boldsymbol{F} \\
& d \boldsymbol{K} / d t=\boldsymbol{M}
\end{aligned}
$$

where $\boldsymbol{Q}$ and $\boldsymbol{K}$ represent the momentum and moment of momentum respectively. $\boldsymbol{F}$ and $\boldsymbol{M}$ are forces and moments within body-fixed frame applying on the BWBUG.

Considering the distance between CG and CB and expressing Eqs. (1) and (2) with respect to CG, Eqs. (3) and (4) is then conducted.

$$
\begin{gathered}
d \boldsymbol{Q} / d t+\boldsymbol{\omega} \times \boldsymbol{Q}=\boldsymbol{F} \\
d \boldsymbol{K} / d t+\boldsymbol{\omega} \times \boldsymbol{K}+\boldsymbol{v}^{\prime} \times \boldsymbol{Q}=\boldsymbol{M}
\end{gathered}
$$

where $\boldsymbol{\omega}$ is the rotating speed and $\boldsymbol{v}^{\prime}$ is the velocity vector of CB. In most cases, the CG and CB have a relatively small difference which means $\boldsymbol{v}^{\prime}$ is approximately equals to $\boldsymbol{v}$. The Eq. (4) can be simplified to Eq. (5).

$$
d \boldsymbol{K} / d t+\boldsymbol{\omega} \times \boldsymbol{K}=\boldsymbol{M}
$$

$\boldsymbol{Q}$ and $\boldsymbol{K}$ are obtained by Eq. (6),

$$
\left[\begin{array}{l}
\boldsymbol{Q} \\
\boldsymbol{K}
\end{array}\right]=\boldsymbol{I}_{\boldsymbol{m}}\left[\begin{array}{c}
\boldsymbol{v} \\
\boldsymbol{\omega}
\end{array}\right]=\left[\begin{array}{cc}
\boldsymbol{m} & m \boldsymbol{r} \\
-m \boldsymbol{r} & \boldsymbol{J}
\end{array}\right]\left[\begin{array}{l}
\boldsymbol{v} \\
\boldsymbol{\omega}
\end{array}\right]
$$

In Eq. (6), $\boldsymbol{Q}=\left[\begin{array}{lll}Q_{x} & Q_{y} & Q_{z}\end{array}\right]^{T}, \quad \boldsymbol{K}=\left[\begin{array}{lll}K_{x} & K_{y} & K_{z}\end{array}\right]^{T}, \boldsymbol{v}=\left[\begin{array}{lll}v_{x} & v_{y} & v_{z}\end{array}\right]^{T}, \boldsymbol{\omega}=\left[\begin{array}{lll}\omega_{x} & \omega_{y} & \omega_{z}\end{array}\right]^{T}=\left[\begin{array}{ll}\dot{\psi} \dot{\varphi} \dot{\theta}\end{array}\right]^{T}$, $\boldsymbol{J}=\left[\begin{array}{ccc}J_{x} & -J_{x y} & -J_{x z} \\ -J_{x y} & J_{y} & -J_{y z} \\ -J_{x z} & -J_{y z} & J_{z}\end{array}\right], \boldsymbol{m}=\left[\begin{array}{ccc}m & 0 & 0 \\ 0 & m & 0 \\ 0 & 0 & m\end{array}\right], \boldsymbol{r}=\left[\begin{array}{ccc}0 & z_{G} & -y_{G} \\ -z_{G} & 0 & x_{G} \\ y_{G} & -x_{G} & 0\end{array}\right] .\left(x_{G},-y_{G}, z_{G}\right)$ is the projection of CG's radius vector in body-fixed frame. $\boldsymbol{J}$ represents the moment of inertia. For BWBUGs included in this paper, $z_{G}=0$ as they share the same symmetry plane XOY. In this paper, $y_{G}$ is negative to generate a restoring moment when there is roll motion. It is also assumed that $J_{x y}=J_{x z}=J_{y z}$ $=0$ as they are too small to affect the results when compared with $J_{x}, J_{y}$ and $J_{z}$. Thus, corresponding terms are eliminated and the glider's motion matrix illustrated by Eq. (7) is deducted. 


$$
\left[\begin{array}{l}
\boldsymbol{Q} \\
\boldsymbol{K}
\end{array}\right]=\left[\begin{array}{c}
Q_{x} \\
Q_{y} \\
Q_{z} \\
K_{x} \\
K_{y} \\
K_{z}
\end{array}\right]=\left[\begin{array}{cccccc}
m & 0 & 0 & 0 & 0 & -m y_{G} \\
0 & m & 0 & 0 & 0 & m x_{G} \\
0 & 0 & m & m y_{G} & -m x_{G} & 0 \\
0 & 0 & m y_{G} & J_{x} & 0 & 0 \\
0 & 0 & -m x_{G} & 0 & J_{y} & 0 \\
-m y_{G} & m x_{G} & 0 & 0 & 0 & J_{z}
\end{array}\right]\left[\begin{array}{c}
v_{x} \\
v_{y} \\
v_{z} \\
\omega_{x} \\
\omega_{y} \\
\omega_{z}
\end{array}\right]
$$

Combine Eqs. (3)-(7) and consider the added mass, get

$$
\left(\boldsymbol{I}_{\boldsymbol{m}}+\boldsymbol{I}_{a}\right)\left[\begin{array}{l}
\frac{d \boldsymbol{v}}{d t} \\
\frac{d \boldsymbol{\omega}}{d t}
\end{array}\right]+\frac{d \boldsymbol{I}_{m}}{d t}\left[\begin{array}{l}
\boldsymbol{v} \\
\boldsymbol{\omega}
\end{array}\right]+\boldsymbol{T}_{r}\left(\boldsymbol{I}_{\boldsymbol{m}}\left[\begin{array}{l}
\boldsymbol{v} \\
\boldsymbol{\omega}
\end{array}\right]\right)=\left[\begin{array}{l}
\boldsymbol{F} \\
\boldsymbol{M}
\end{array}\right]
$$

where $\boldsymbol{I}_{a}$ is the added mass matrix and $I_{a i j}=\lambda_{i j}, i=1,2, \ldots, 6, j=1,2, \ldots, 6 . \boldsymbol{T}_{r}$ represents the rotating

matrix where $\boldsymbol{T}_{\boldsymbol{r}}=\left[\begin{array}{cccccc}0 & -\omega_{z} & \omega_{y} & 0 & 0 & 0 \\ \omega_{z} & 0 & -\omega_{x} & 0 & 0 & 0 \\ -\omega_{y} & \omega_{x} & 0 & 0 & 0 & 0 \\ 0 & -v_{z} & v_{y} & 0 & -\omega_{z} & \omega_{y} \\ v_{z} & 0 & -v_{x} & \omega_{z} & 0 & -\omega_{x} \\ -v_{y} & v_{x} & 0 & -\omega_{y} & \omega_{x} & 0\end{array}\right]$. The rest forces are composed by

hydrodynamic forces, buoyancy and gravity. The hydrodynamic forces are defined by velocity while the buoyancy and gravity are defined within earth-fixed frame. By projecting buoyancy and gravity to velocity directions, Eq. (9) is then obtained.

$$
\left[\begin{array}{l}
\boldsymbol{F} \\
\boldsymbol{M}
\end{array}\right]=\left[\begin{array}{l}
-K v^{2} C_{x}(\alpha, \beta)-\Delta B \sin \theta \\
K v^{2}\left[C_{y}(\alpha, \beta)+C_{y}^{\bar{\omega}_{z}} \bar{\omega}_{z}\right]-\Delta B \cos \theta \cos \psi \\
K v^{2}\left[C_{z}(\beta)+C_{z}^{\bar{\omega}_{y}} \bar{\omega}_{y}+C_{z}^{\bar{\omega}_{x}} \bar{\omega}_{x}\right]+\Delta B \cos \theta \sin \psi \\
K L v^{2}\left(m_{x}^{\bar{\omega}_{x}} \bar{\omega}_{x}+m_{x}^{\bar{\omega}_{y}} \bar{\omega}_{y}\right)+\Delta B \cos \theta\left(y_{G} \sin \psi\right) \\
K L v^{2}\left[m_{y}(\beta)+m_{y}^{\bar{\omega}_{x}} \bar{\omega}_{x}+m_{y}^{\bar{\omega}_{y}} \bar{\omega}_{y}\right]-\Delta B\left(x_{G} \cos \theta \sin \psi\right) \\
K L v^{2}\left[m_{z}(\alpha)+m_{z}^{\bar{\omega}_{z}} \bar{\omega}_{z}\right]+\Delta B\left(y_{G} \sin \theta-x_{G} \cos \theta \cos \psi\right)
\end{array}\right]
$$

Where, $K=\rho S / 2, \Delta B=B-G, \alpha=\arctan \left(-v_{y} / v_{x}\right), \beta=\arctan \left(v_{z} / \sqrt{v_{x}^{2}+v_{y}^{2}}\right), C_{i}$ and $m_{i}$ represent hydrodynamic coefficients while $C_{i}^{\bar{\omega}_{j}}$ and $m_{i}^{\bar{\omega}_{j}}$ are forces and moment coefficient along the degree of freedom $i$ caused by the motion along the degree of freedom $j$. .

Differ to conventional underwater vehicles, underwater glider uses the buoyancy regulating device to change its wet mass and CG. The moment of inertia is changed as a result. When expanding $d \boldsymbol{I}_{\boldsymbol{m}} / d t$ in Eq. (8), then

$$
\frac{d \boldsymbol{I}_{m}}{d t}=\left[\begin{array}{cccccc}
\dot{m} & 0 & 0 & 0 & 0 & -\dot{m} y_{G} \\
0 & \dot{m} & 0 & 0 & 0 & \dot{m} x_{G}+m \dot{x}_{G} \\
0 & 0 & \dot{m} & \dot{m} y_{G} & -\dot{m} x_{G}-m \dot{x}_{G} & 0 \\
0 & 0 & \dot{m} y_{G} & \dot{J}_{x} & 0 & 0 \\
0 & 0 & -\dot{m} x_{G}-m \dot{x}_{G} & 0 & \dot{J}_{y} & 0 \\
-\dot{m} y_{G} & \dot{m} x_{G}+m \dot{x}_{G} & 0 & 0 & 0 & \dot{J}_{z}
\end{array}\right]
$$


Based on Eq. (10), the moment of inertial is matters of time-varying variables including $\dot{m}, \dot{x}_{G}, \dot{J}_{y}$ and $\dot{J}_{z}$, in addition to constant variable. Thus, a buoyancy regulating model is then established to study how the variable will change during gliding motion.

\subsection{Buoyancy and pitch regulating model for BWBUG}

The buoyancy and pitch regulating system (BPRS) of BWBUG is composed by buoyancy regulating system (BRS) and pitch regulating system (PRS). The BRS consists of a regulating tank with piston, oil bladder and the oil tank. The PRS is assembled by a motor and the battery pack. The inner device distribution of the BWBUG is shown in Fig. 3. In which $l_{l}, l_{2}$ and $D_{l}$ refer to the location of the piston, location of the battery pack and the diameter of the piston respectively.

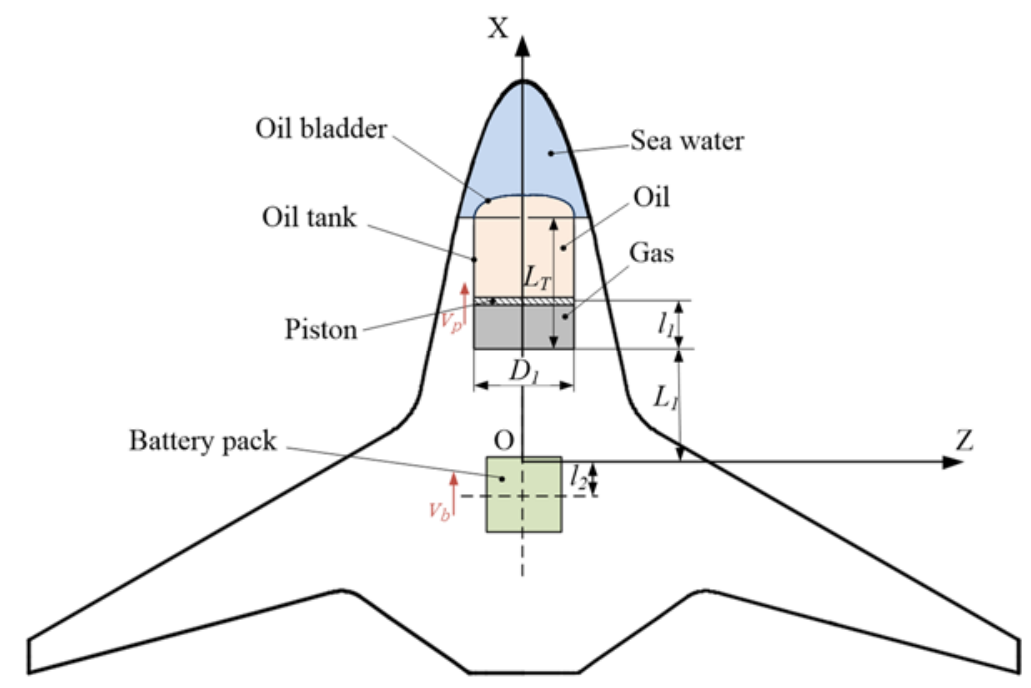

Fig. 3. Buoyancy and pitching regulating system (BPRS). Motors to drive the piston and battery pack are not shown.

In most condition, BWBUG glides through a certain range under the sea surface and rise to the surface to upload data and download instructions after finishing a certain number of steady gliding period. The gliding trajectory under sea surface is a mainly concern in this paper, and the trajectory rising to the sea surface is not included. As shown by Fig. 4, a gliding period consists of diving phase (from $B$ to $E$ ) and rising phase (from $\mathrm{E}$ to $\mathrm{H}$ ). To start the diving period, the motor starts working at A and drives the battery pack to move forward. At the same time, the piston moves backward and the oil bladder shrinks to decrease the buoyancy. As long as $\Delta B$ is negative, the BWBUG starts to dive. The motor continues working until reach a steady gliding phase at $C$. When a certain depth is reached, the oil is pumped out of the regulating tank into the bladder and the battery pack is moved backward. The BWBUG will transfer to steady rising phase as a result. Gliding ratio, as an essential character of trajectory, is defined by Eq. (11).

$$
R_{g}=\frac{D_{h}}{2 \Delta h}
$$

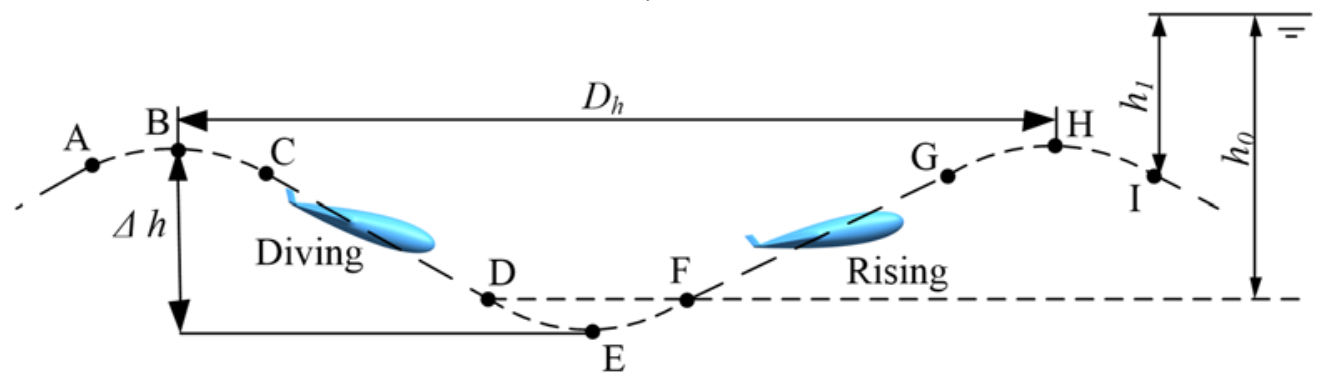


Fig. 4. Gliding path including rising-to-diving regulating phase (AC), steady diving phase (CD), divingto-rising regulating phase (DF), steady rising phase (FG) and new rising-to-diving regulating phase (GI).

During the regulating procedure, the moment of inertia, center of gravity is affected by the inner device. Let the speed of the battery pack and piston be $v_{b}$ and $v_{p}$. Then $x_{G}, \dot{m}, \dot{x}_{G}, \dot{J}_{y}, \dot{J}_{z}$ in Eq. (10) can be calculated.

$$
\begin{gathered}
x_{G}=\frac{\sum m_{i} x_{i}}{\sum m_{i}}=\frac{m_{o i l} x_{o i l}+m_{w} x_{w}+m_{b} x_{b}+m_{o} x_{o}}{m_{o i l}+m_{w}+m_{b}+m_{o}} \\
\dot{m}=\dot{m}_{w}=-\frac{\pi D_{1}^{2}}{4} \rho_{w} v_{p} \\
\dot{x}_{b}=v_{b}
\end{gathered}
$$

where, the index $w, b, o$ represent water inside the glider, battery pack and other parts of the BWBUG respectively.

Based on Eq. (12), then

$$
\dot{x}_{G}=\frac{\sum\left(m_{i} x_{i}\right)^{\prime} \sum m_{i}-\sum m_{i} x_{i}\left(\sum m_{i}\right)^{\prime}}{\left(\sum m_{i}\right)^{2}}=\frac{\left(m_{o i l} \dot{x}_{o i l}+\dot{m}_{w} x_{w}+m_{w} \dot{x}_{w}+m_{b} \dot{x}_{b}\right)-x_{G} \dot{m}_{w}}{\left(m_{o i l}+m_{w}+m_{b}+m_{o}\right)}
$$

Assume that the shape if the oil bladder during the adjusting procedure remains to be cylindrical with the diameter $D_{l}$, then

$$
\dot{x}_{\text {oil }}=\dot{x}_{w}=v_{p}
$$

The differential of moment of inertia, expressed in Eq. (17), is determined only by the movable masses e.g. water inside the underwater glider, oil in the tank and bladder, and the battery pack.

$$
\dot{J}_{z}=\dot{J}_{z w}+\dot{J}_{z o}+\dot{J}_{z b}=\frac{d}{d t}\left(m_{w} x_{w}^{2}+m_{o i l} x_{o i l}^{2}+m_{b} x_{b}^{2}\right)
$$

Express the mass with density and volume, get.

$$
\begin{gathered}
m_{\text {oil }}=\frac{1}{4} \rho \pi D_{1}^{2} L_{T} \\
m_{w}=m_{w 0}-\frac{1}{4} \rho \pi D_{1}^{2} l_{1}
\end{gathered}
$$

where $m_{w 0}$ represents the mass of water when $l_{l}=0$. Replace the coordination with the distance shown in Fig. 3, Eq. (20) are obtained.

$$
\begin{gathered}
x_{w}=L_{1}+\frac{l_{1}}{2}+L_{T} \\
x_{\text {oil }}=L_{1}+l_{1}+\frac{L_{T}}{2} \\
x_{b}=-l_{2}
\end{gathered}
$$

$\dot{J}_{y}$ and $\dot{J}_{z}$ are calculated by combining Eqs. (17)-(20) and expressed by pre-defined parameters or variables.

$$
\begin{aligned}
\dot{J}_{y} & =\dot{J}_{z}=\dot{J}_{z w}+\dot{J}_{z o}+\dot{J}_{z b} \\
& =\frac{\pi D_{1}^{2}}{4} \dot{l}_{1}\left[2 \rho_{o i l} L_{T}\left(L_{1}+\frac{L_{T}}{2}+l_{1}\right)-\rho_{w}\left(L_{1}+L_{T}+\frac{l_{1}}{2}\right)\left(L_{1}+L_{T}+\frac{3 l_{1}}{2}\right)\right]+2 m_{b} l_{2} v_{b}
\end{aligned}
$$

The gliding motion of BWBUG can be obtained by solving Eq. (8) and the trajectory of the BWBUG in earth-fixed frame is established as a consequence. Fig. 5 illustrates the framework of the process is divided into two modules. The CFD calculation module begins with geometry configuration of BWBUG and end with hydrodynamic performance as output. In the CFD calculation module, the commercial software FLUENT is used to calculate the hydrodynamic coefficient in Eq. (9). The 
trajectory calculation module takes hydrodynamic performance and parameters of BPRS as input. By solving the kinematics and dynamics equation, the trajectory information is obtained and taken as output.

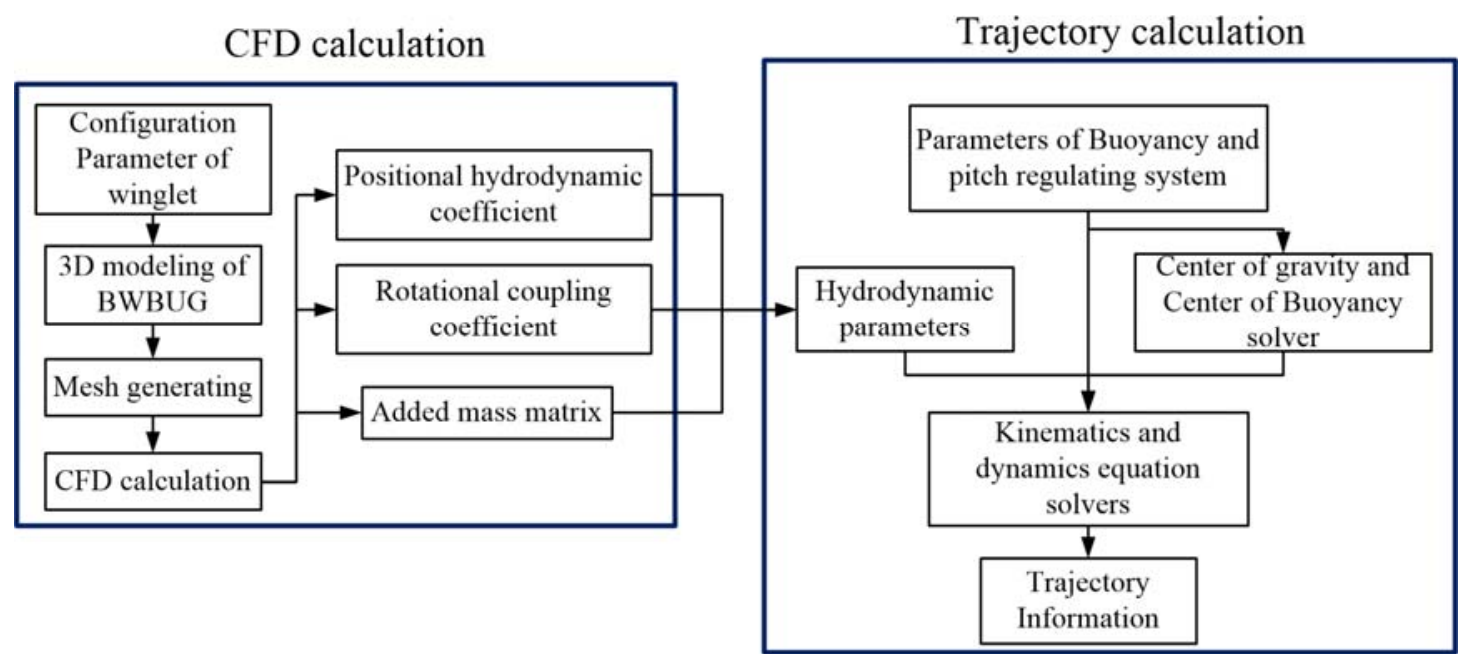

Fig. 5. A Framework to obtain the gliding trajectory.

\section{CFD calculation and validation}

\subsection{Numerical Validation}

The Navier-Stokes equations and continuity equations which described the incompressible fluid are considered as governing equations in this paper. The incompressible character of the fluid is described by Eq. (22) while the continuity and momentum conservation are governed by Eq. (23)

$$
\begin{aligned}
& \nabla \cdot U=0 \\
& \rho \frac{d U}{d t}=\rho g-\nabla p+\mu \nabla^{2} U
\end{aligned}
$$

where $U$ represents the velocity vector, $\rho$ represents density. $p$ and $\mu$ represent pressure and viscosity, respectively. In addition, SST $k-\omega$ model is adopted in this paper to close the governing equations.

Before applying CFD method to calculating the hydrodynamic characters, the validation works are carried out. Zarruk et al. (Zarruk et al., 2014) studied the hydrodynamic and hydro-elastic performance by water tunnel experiment. The experiment results for standard NACA0009 made of aluminum are selected, considering the condition for the hydrofoil is similar to that of BWBUG. A total of 4 sets of mesh is generated to compare when Reynolds number is $1 \times 10^{6}$. The main difference for the meshes are the mesh distribution $\left(\mathrm{Y}^{+}\right)$within the inflation layer, total mesh numbers which are listed in Table 1. Lift coefficient and drag coefficient are compared in Fig. 6 in which the results of Mesh 4 shows good accordance with the reference data. In the following of this paper, the mesh for BWBUG used in CFD calculation is generated based on the parameters of Mesh 4.

Table 1 Mesh used in comparison

\begin{tabular}{lcc}
\hline & Mesh number & $\mathrm{Y}^{+}$ \\
\hline Mesh1 & 430,540 & 1 \\
Mesh2 & 752,230 & 5 \\
Mesh3 & $1,300,040$ & 1 \\
Mesh4 & $2,240,660$ & 5 \\
\hline
\end{tabular}



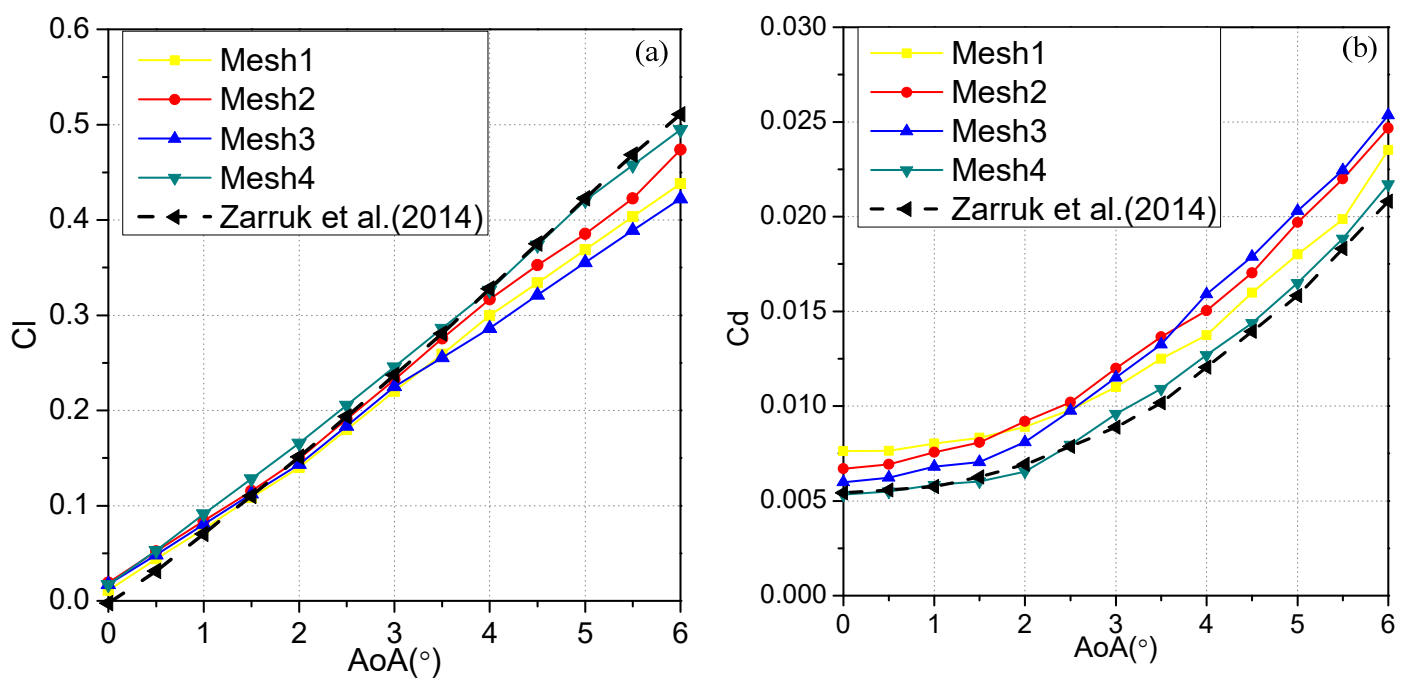

Fig. 6. Nondimensional coefficients for (a) lift coefficient and (b) drag coefficient against attack angle (AoA). The experimental result from Zarruk et al.(Zarruk et al., 2014) is used for comparison.

\subsection{CFD Calculation of BWBUG}

The hydrodynamic characters, including profiling characters and sliding characters, are calculated in this paper. As shown in Fig. 7 (a) and (b), meshes are firstly generated both for the BWBUG-I and BWBUG-II based on the same mesh generating tropology. The attitude angles, including attack angle (AoA) and sliding angle, are then given by changing the flow direction. Fig. 7 (c) illustrate the boundary condition when there is attack angle: The front and bottom of the domain are defined as velocity inlet while the top and back of the domain are defined as pressure outlet. To generate the sliding angle, the front and one side (left/right) of the domain are defined as velocity inlet while the back and the other side of the domain are defined as pressure outlet. The size of the computational domain is $\left[-5 C_{\mathrm{t}}, 10 C_{\mathrm{t}}\right] \times\left[-5 C_{\mathrm{t}}, 5 C_{\mathrm{t}}\right] \times\left[-5 C_{\mathrm{t}}, 5 C_{\mathrm{t}}\right]$, where $C_{\mathrm{t}}$ represents the chord length of BWBUG and the coordinate origin is $\mathrm{CB}$ of BWBUG. In addition to steady characters, damping character and added mass are calculated before establishing the dynamic model for BWBUG. 

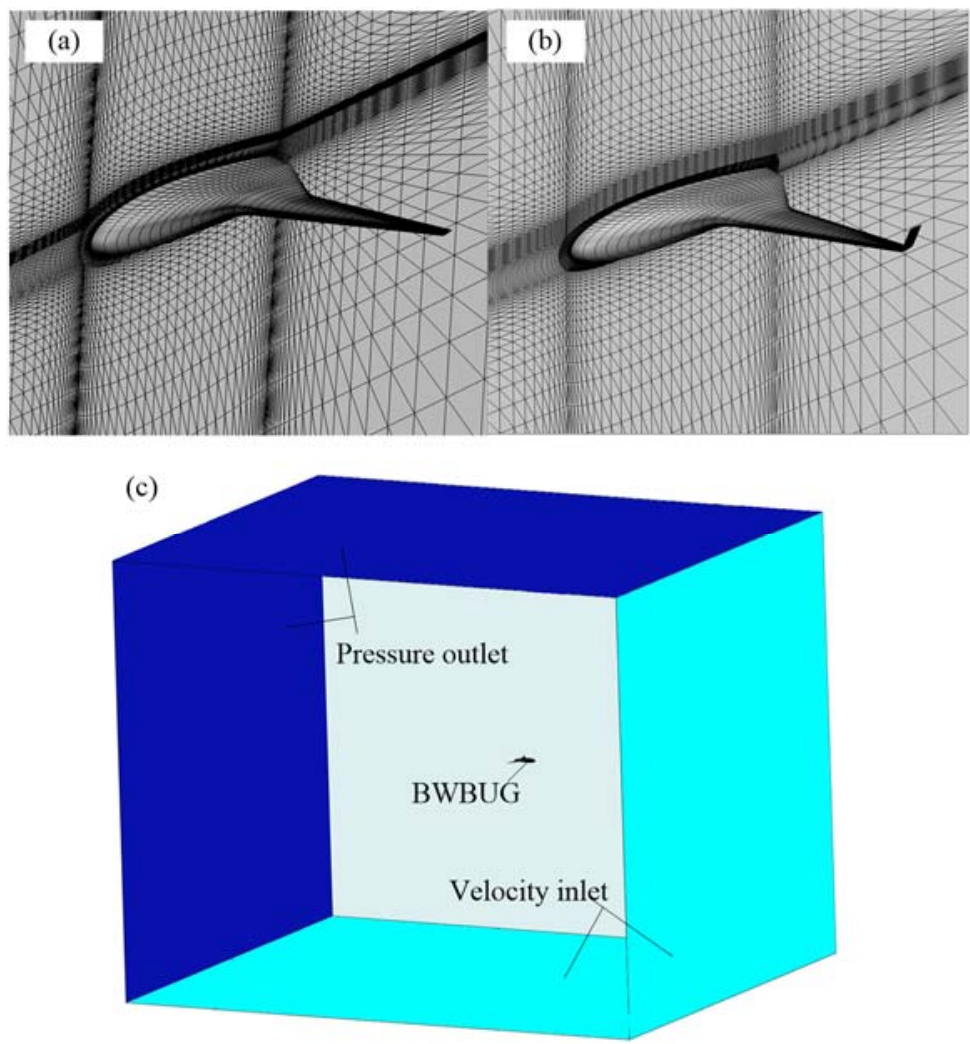

Fig. 7. Mesh for (a) BWBUG-I, (b) BWBUG-II and (c) computational domain to perform the CFD calculation. The front and bottom of the domian is defined as velocity inlet to generate an attack angle.

\section{Results and discussion}

\subsection{Hydrodynamic performance}

CFD simulation is carried out under different velocity to study the influence of gliding speed on hydrodynamic performance of two BWBUGs discussed in this paper. Two typical velocities, $1 \mathrm{~m} / \mathrm{s}$ and $0.5 \mathrm{~m} / \mathrm{s}$ are chosen considering that most underwater glider now gliding around $0.5 \mathrm{~m} / \mathrm{s}$ and it is possible to increase the speed to $1 \mathrm{~m} / \mathrm{s}$ by improving the capacity of buoyancy regulating device (Sun et al., 2017).

The relation between hydrodynamic forces and attitude angle are shown in Fig. 8. All of the results are obtained when the attitude angle varies within $-8^{\circ}$ to $8^{\circ}$. It is observed in Fig. 8(a) and (b) that lift and drag are four times larger when the gliding speed is $1 \mathrm{~m} / \mathrm{s}$ than $0.5 \mathrm{~m} / \mathrm{s}$. In the meanwhile, the lift force of BWBUGs grows linearly with the attack angle while the drag force of BWBUGs witnesses a square increase. Comparison between BWBUG-I and BWBUG-II reveals that the lift force of BWBUG-II is slightly higher than that of BWBUG-I under two specified velocity. However, the drag remains at the same level for two BWBUGs under the same condition. The lift-to-drag ratio, as shown in Fig. 8(c), is influenced both by gliding velocity and winglet when attack angle is the same. For a given BWBUG, a higher velocity leads to a higher lift-to-drag ratio, while for a given velocity, BWBUG-II with winglet tends to have a higher lift-to-drag ratio. More specifically, BWBUG-II with $0.5 \mathrm{~m} / \mathrm{s}$ has a similar lift-to-drag ratio to BWBUG-I with $1 \mathrm{~m} / \mathrm{s}$, indicating that the requirement for the buoyancy regulating device can be reduced by winglet to achieve a required gliding velocity. In other words, it is easier for BWBUG-II to achieve a balance in terms of force with a smaller attack angle, when the velocity is determined. Fig. 8(d) present the pitch moment, which decreases with increase in attack angle. The magnitude of moment follows the force to grow in a square relation when velocity rises. Comparison shows that winglet applied on 
BWBUG-II contributes to reducing the pitch moment when compared to BWBUG-I. In this case, the steady character in profiling plane is affected by winglet. However, based on Fig. 9(b) the restoring moment is increased for BWBUG-II when compared to BWBUG-I. Besides, the BPRS can make up the negative impact the winglet brings to profiling characters. The sway force shown in Fig. 9(a) increases with slide angle, with the same regular the lift force increases with attack angle. The trajectory within profiling plane is simulated by MATALB Simulink, based on the hydrodynamic coefficient obtained by CFD calculation. The detailed hydrodynamic parameters for BWBUG-I and BWBUG-II is listed in Appendix B.

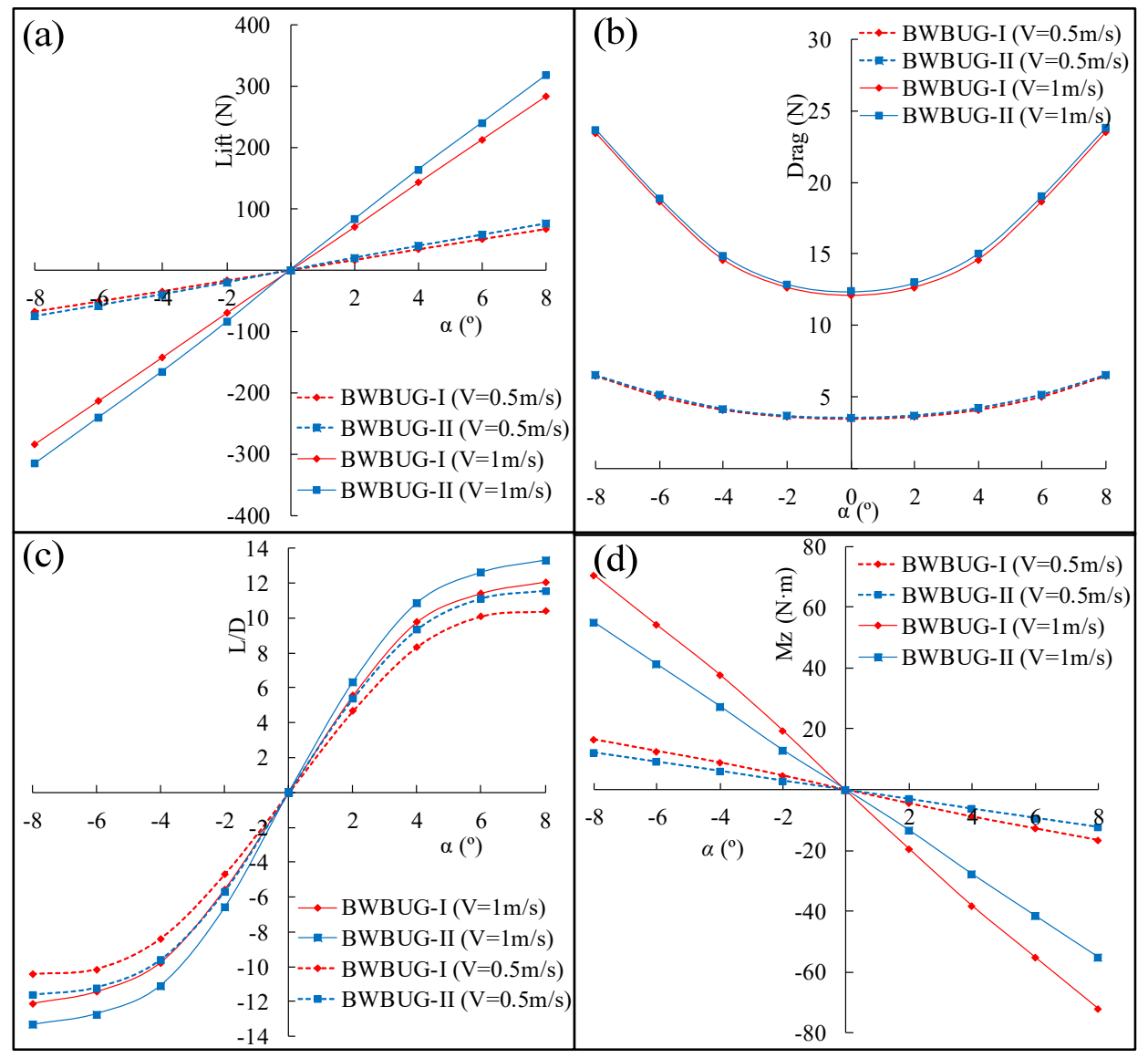

Fig. 8. Profiling characters for BWBUG-I and BWBUG-II. (a) Lift against attack angle. (b) Drag against attack angle. (c) Lift-to-drag ratio against attack angle and (d) Pitch moment against attack angle.

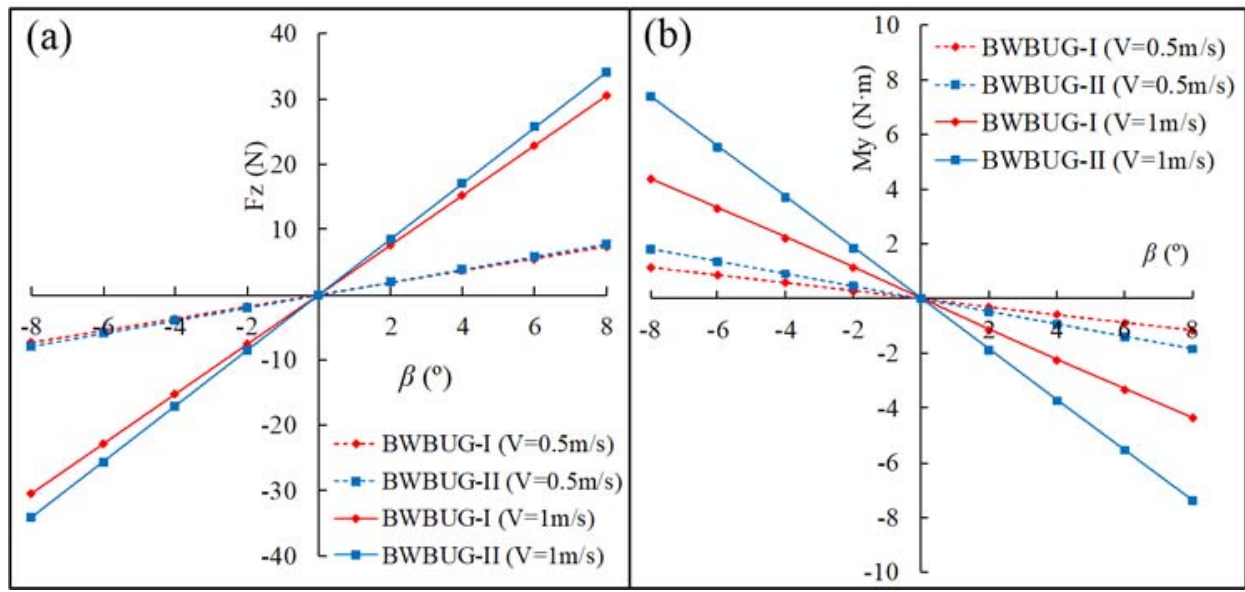

Fig. 9. Lateral characters for BWBUG-I and BWBUG-II including (a) Lateral force against sliding angle and (b) Yaw moment against sliding angle. 


\subsection{Stability of BWBUG}

In this paper, restoring forces, in addition to restoring moment, lead to a stable trajectory and keep the BWBUG to move straight forward without any extra control. Other methods to ensure the dynamic stability, such as using control surface like rudders or internal mass, are additional ways to keep the BWBUG stable. However, the sailing range is sacrificed due to energy consumption when using the additional methods to keep a straight trajectory.

The static stability is characterized by the restoring moments and forces. The pitch moment and yaw moment are restoring moment in profiling plane and horizontal plane, respectively. Based on Fig. 8(d) and Fig. 9(b), the restoring moment can be expressed by Eq.(24) when the attack/slip angle varies between $-8^{\circ}$ and $8^{\circ}$.

$$
\left\{\begin{array}{l}
M_{z}(\alpha)=K L v^{2} m_{z}^{\alpha} \alpha \\
M_{y}(\beta)=K L v^{2} m_{y}^{\beta} \beta
\end{array}\right.
$$

where, $m_{z}^{\alpha}$ and $m_{y}^{\beta}$ are restoring moment coefficient with negative value while providing overturning moment when negative. The ratio of restoring moment against attitude angle are listed in Table 2, showing that the magnitude of the restoring moment is proportional to velocity square. Comparison between BWBUG-I and BWBUG-II under the same velocity reveals that the winglet applied on BWBUG-II reduced the restoring moment within the vertical plane, as the slope ratio of pitch moment against attack angle $M_{z}^{\alpha}$ decrease by $31.6 \%$ and $28.3 \%$ when the gliding speed is $0.5 \mathrm{~m} / \mathrm{s}$ and $1 \mathrm{~m} / \mathrm{s}$ respectively. However, the slope ratio of pitch moment against slip angle $M_{y}^{\beta}$ increases by $59.7 \%$ and 59.3\% respectively. The winglet applied on BWBUG-II negatively influence the stability within the vertical plane while positively affect the stability within the horizon plane. In terms of restoring moment, the positive influence overweighs the negative one.

Table 2 Restoring characters of BWBUG-I and BWBUG-II

\begin{tabular}{ccccc}
\hline & \multicolumn{2}{c}{$v=0.5 \mathrm{~m} / \mathrm{s}$} & \multicolumn{2}{c}{$v=1 \mathrm{~m} / \mathrm{s}$} \\
\hline & $M_{z}^{\alpha}(\mathrm{N} \cdot \mathrm{m} / \mathrm{deg})$ & $M_{y}^{\beta}(\mathrm{N} \cdot \mathrm{m} / \mathrm{deg})$ & $M_{z}^{\alpha}(\mathrm{N} \cdot \mathrm{m} / \mathrm{deg})$ & $M_{y}^{\beta}(\mathrm{N} \cdot \mathrm{m} / \mathrm{deg})$ \\
BWBUG-I & -2.21 & -0.144 & -9.02 & -0.58 \\
BWBUG-II & -1.51 & -0.230 & -6.46 & -0.924 \\
\hline
\end{tabular}

The stability criterion in vertical plane and horizon plane is expressed by Eqs.(25) and (26) respectively.

$$
\begin{aligned}
& \bar{L}_{\omega_{z}}=\frac{m_{z}^{\alpha}}{C_{y}^{\alpha}} \\
& \bar{L}_{\omega_{y}}=\frac{m_{y}^{\beta}}{C_{z}^{\beta}}
\end{aligned}
$$

Where, $\bar{L}_{\omega_{z}}$ and $\bar{L}_{\omega_{y}}$ represent the static margin within vertical plane and horizontal plane, respectively. The static margin under different velocity for BWBUG-I and BWBUG-II is calculated and listed in Table 3. Similar to the restoring moment, the underwater glider without winglet shows a static margin in the vertical plane under both velocity while has a narrower static margin in horizon plane, when compared to BWBUG-II. The static margin both witness a decrease when the velocity increases from $0.5 \mathrm{~m} / \mathrm{s}$ to $1 \mathrm{~m} / \mathrm{s}$, revealing that a higher velocity for BWBUG may resulted in unstable conditions.

Table 3 Static margin of BWBUG-I and BWBUG-II under different velocity

$v=0.5 \mathrm{~m} / \mathrm{s} \quad v=1 \mathrm{~m} / \mathrm{s}$




\begin{tabular}{ccccc}
\hline & $\bar{L}_{\omega_{z}}$ & $\bar{L}_{\omega_{y}}$ & $\bar{L}_{\omega_{z}}$ & $\bar{L}_{\omega_{y}}$ \\
BWBUG-I & -0.138 & -0.088 & -0.136 & -0.084 \\
BWBUG-II & -0.089 & -0.130 & -0.080 & -0.121 \\
\hline
\end{tabular}

\subsection{Trajectory of BWBUG-I and BWBUG-II within profiling plane}

The trajectory in profiling plane is firstly carried out for BWBUGs based on the dynamic model, pitch and buoyancy regulating model, and the hydrodynamic characters. The Gliding velocity and rotating of BWBUG is obtained by solving Eq. (8). By integrating the velocity and rotating speed, the displacement and attitude of BWBUG is then obtained. The influence of gliding range and capability of buoyancy and pitch regulating system (BPRS) to steady gliding trajectory and regulating trajectory are studied. The initial parameters for BPRS are listed in Table 4 . The initial parameters are used to study the influence of gliding depth on gliding trajectories, after which the parameters are changed to carry out their influence on trajectories of the two gliders.

Table 4 Initial parameters for BPRS

\begin{tabular}{lcll}
\hline \multicolumn{2}{l}{ Buoyancy regulating system } & Pitch regulating system \\
\hline Capacity & Regulating speed & Mass of battery pack & Velocity \\
$\pm 10 \mathrm{~L}\left(0.01 \mathrm{~m}^{3}\right)$ & $20 \mathrm{~L} / \min \left(3.33 \times 10^{-4} \mathrm{~m}^{3} \cdot \mathrm{s}^{-1}\right)$ & $20 \mathrm{~kg}$ & $0.05 \mathrm{~m} \cdot \mathrm{s}^{-1}$ \\
\hline
\end{tabular}

The gliding range is a pre-set parameter for underwater gliders which is determined by two depth, $h_{0}$ and $h_{l}$, as shown in Fig. $4 . h_{0}$ is the target depth for BWBUG which is limited by the structure of pressure hulls while $h_{1}$ is the target ceiling of the BWBUG which can be varies to change the gliding range. In Fig. 10, the trajectories of BWBUG different ceiling depth is shown while the target gliding depth is fixed to $100 \mathrm{~m}$. The steady gliding ratios for BWBUG-I are 5.05 in diving phase and 4.92 in rising phase while the values for BWBUG-II are 5.18 and 5.01, respectively, regardless of ceiling depth. The average gliding ratios in one period are 4.99 and 5.10 for BWBUG-I and BWBUG-II. In other words, the ceiling depth did not affect the slope ratio of steady gliding as the steady gliding trajectory are parallel for each BWBUG. However, a narrow gliding range leads to more frequent use of buoyancy and BPRS to reach the same gliding range. During simulation, the BPRS is activated when the pre-set depth is reached. In this case, there is a squat trajectory due to the lag in switching from diving to rising or from rising to diving. A too deep trajectory will result in failure of structure and too shallow trajectory will cause the BWBUG to rise to the sea surface, which should be avoided.

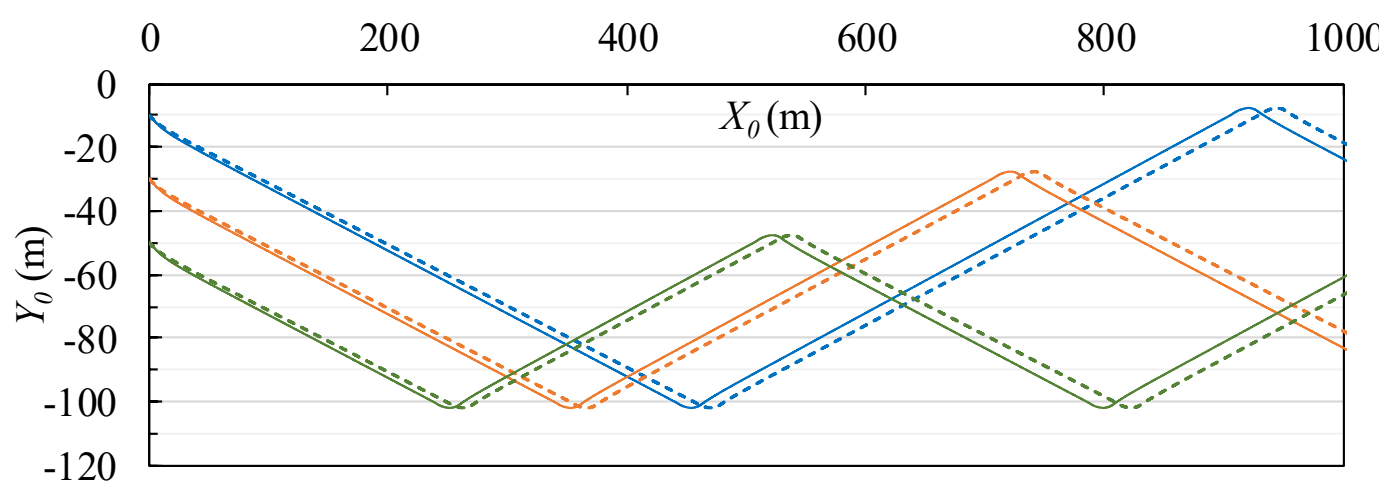

Fig. 10. Gliding trajectories within profiling plane including BWBUGs without winglet (dashed lines) and with winglet (solid lines) when gliding with different ceiling depth (blue lines for $-10 \mathrm{~m}$, orange lines for $-30 \mathrm{~m}$ and green lines for $-50 \mathrm{~m}$ ). 

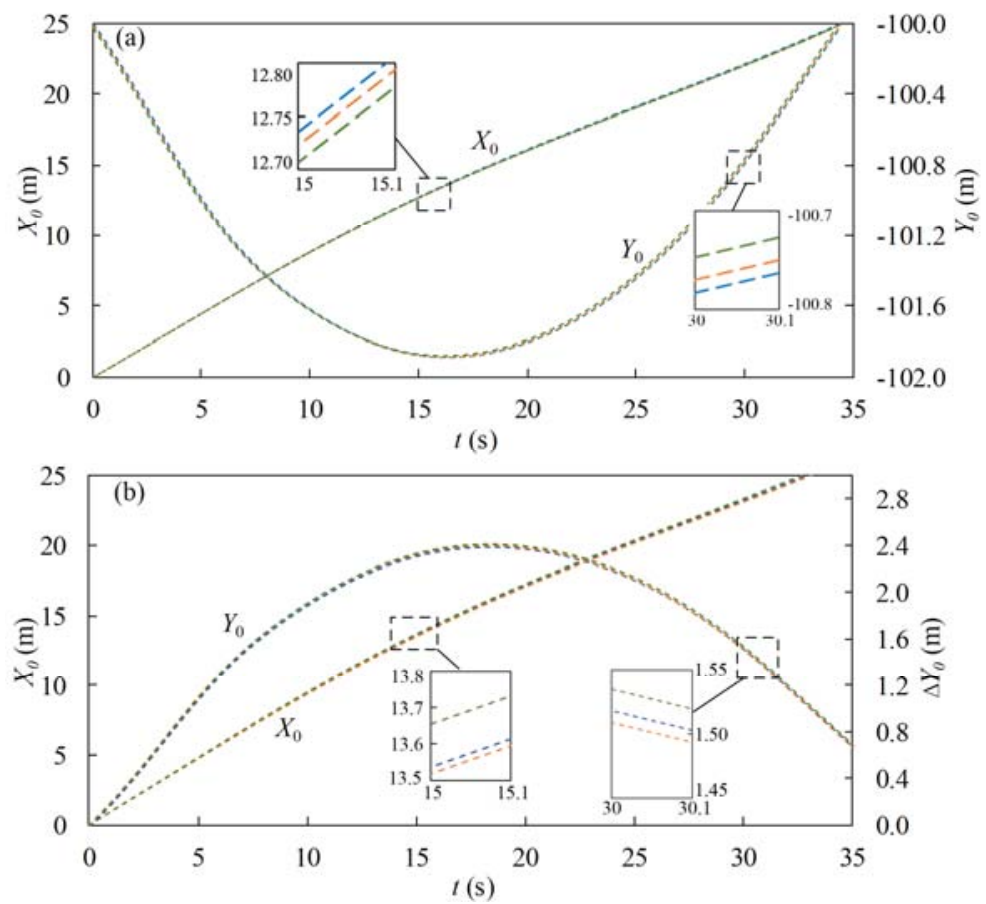

Fig. 11. Time histories for horizontal and vertical displacement of BWBUG gliding through different ceiling depth (blue lines for $-10 \mathrm{~m}$, orange lines for $-30 \mathrm{~m}$ and green lines for $-50 \mathrm{~m}$ ) during (a) DTRRP and (b) RTDDP.

To investigate the ceiling depth impact on regulating trajectories, BWBUG-I with different ceiling depth is chosen to study in detail the trajectories in regulating phases. Fig. 11 illustrate the horizontal displacement of BWBUG-I and depth over time, respectively. At the moment $t=0$, the glider reaches the target gliding depth when the BPRS starts to work. In Fig. 11(a), the ratio of $X_{0}$ witnesses a slight decrease which demonstrate the decrease of horizontal speed within the procedure. However, the vertical speed witnesses a decrease before reaching the bottom of the gliding trajectory after which the vertical speed is reversed and increased gradually. In Fig. 11(b), $X_{0}$ witnesses a sharper increase when compared to Fig. 11(a) which reveal that the horizontal gliding velocity is higher at the peak of trajectory than that of near the bottom of the trajectory. In terms of vertical velocity, $\Delta Y_{0}$ is defined based on $h_{0}$ and the squat when converting from rising to diving is $2.4 \mathrm{~m}$, larger than $1.9 \mathrm{~m}$ when converting from dive to rise. For the initial BPRS, the buoyancy regulating capacity is $\pm 10 \mathrm{~L}$, the drainage speed is $20 \mathrm{~L} / \mathrm{min}\left(3.33 \times 10^{-4} \mathrm{~m}^{3} \cdot \mathrm{s}^{-1}\right)$ which means the BRS keeps working for $30 \mathrm{~s}$ in the regulating procedure. However, the vertical speed takes about $16 \mathrm{~s}$ to decrease to zero after BPRS is activated. The PRS works for a longer time than BRS to establish a new steady gliding condition. The difference between DTRRP and RTDRP is probably due to the difference in the initial condition. Thus, more detailed trajectories information needs to be studied and how the winglet has an influence on the regulating trajectories need to be clarified.

BWBUG-I and BWBUG-II are compared in Fig. 12 to specify the influence of winglet during DTRRP and RTDDP within profiling plane. The trajectories, as well as the attack angle regulating history and slope angle history, are considered. Fig. 12(a) and (b) presents trajectories for two BWBUGs in detail from which it can be concluded that the BWBUG-II needs more space than BWBUG-I in horizontal direction to switch from one phase to another while for space needed in vertical direction for BWBUG-I is slightly more than that for BWBUG-II. Fig. 13(a) and (b) shows the history of pitch angle during the regulating. The pitch angle is integrated from the rotating speed. For RTDRP, the pitch angle of two gliders increase simultaneously and reach a peak when $\mathrm{t}=5 \mathrm{~s}$. 
Then the angle started to decrease until $\mathrm{t}=20 \mathrm{~s}$, since when the BWBUG-II experience a faster decrease than BWBUG-I. After $t=30 \mathrm{~s}$, the pitch angle reaches the bottom around $t=32 \mathrm{~s}$, before turning to increase thereafter. The pitch angle for DTRRP witness a contrary trend with that for RTDRP, as the pitch angle decreases at first and increase to reach its peak, after which turns to decrease again. The pitch angle varies between $-8.5^{\circ} \sim 11.2^{\circ}$ and $-12.3^{\circ} \sim 11.4^{\circ}$ for BWBUG-I and BWBUG-II during the RTDRP respectively and $-10.1^{\circ} \sim 8.9^{\circ}$ and $-10.3^{\circ} \sim 12^{\circ}$ for BWBUG-I and BWBUG-II during the DTRRP, according to the simulation results. Fig. 13(c) and (d) reveals the history of attack angle during the regulating. The attack angle is negative when rising and positive when diving for both gliders. Different to the pitch angle, the attack angle of BWBUG-II varies with a narrower range than that of BWBUG-I both for DTRRP and RTDRP. The maximum and minimum attack angle are $7^{\circ}$ and $-7^{\circ}$ for BWBUG-I during regulating procedure and the corresponding attack angle are $6^{\circ}$ and $-6^{\circ}$ for BWBUG-II at the same condition. The results reveal that the improvement in hydrodynamic performance bring by winglet also helps to reduce the extreme attack angle during the regulating procedure. This means the winglet also contribute to the safety of the BWBUG considering that a large attack angle may result in stall which should be avoided at any time. In the rest part of this paper, the ceiling depth is fixed to $10 \mathrm{~m}$.
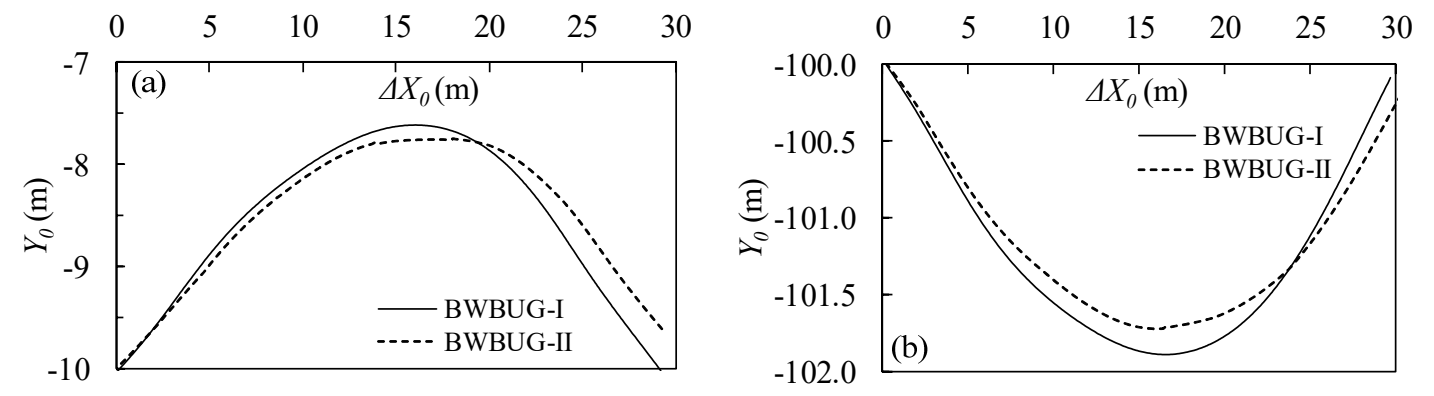

Fig. 12. Trajectories of underwater gliders for (a) RTDRP and (b) DTRRP. The displacement alone $X$ direction is set to 0 at the time when BPRS starts to work. 

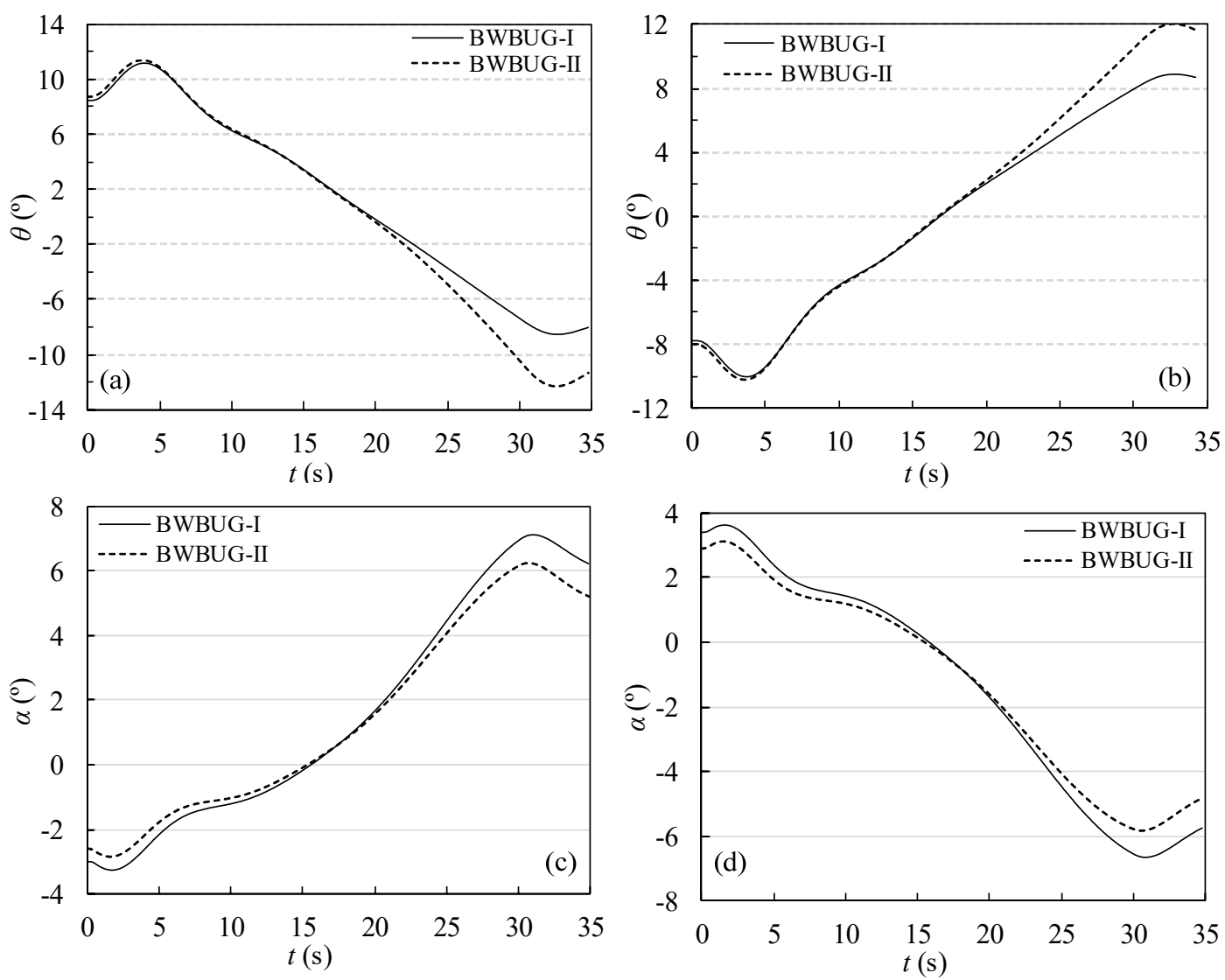

Fig. 13. Time histories of (a) pitch in RTDRP, (b) pitch in DTRRP, (c) attack angle in RTDRP and (d) attack angle in DTRRP.

\subsection{Influence of BPRS on trajectory}

The influence of BPRS on trajectory consists of two parts, the influence on the steady gliding and the influence on regulating procedure. The forces and moments implied on BWBUG are balanced during steady gliding. In this case, the steady gliding motion is not only affected by the hydrodynamic forces, but also influenced by the inner device characters. In this paper, the buoyancy regulating system play the main role to change the buoyancy while the pitch regulating system plays a coordination role to regulating the attitude during the regulating procedure. Thus, the steady gliding motion is affected by buoyancy regulating capacity of buoyancy regulating system and mass of the battery pack of pitch regulating system. However, the regulating trajectory is affected by the buoyancy regulating speed and velocity of the battery pack.

To study the influence of regulating capacity, the flow rate is fixed to $20 \mathrm{~L} / \mathrm{min}\left(3.33 \times 10^{-4} \mathrm{~m}^{3} \cdot \mathrm{s}^{-1}\right)$ while the moving speed of the battery pack is fixed to $0.05 \mathrm{~m} / \mathrm{s}$. Based on Fig. 14, the gliding ratio decreases linearly with the buoyancy regulating capacity for both BWBUG-I and BWBUG-II when the buoyancy regulating capacity varies between $20 \mathrm{~L}$ and $26 \mathrm{~L}$. The gliding ratio turns to increase slower when the buoyancy regulating capacity keeps decreasing under $18 \mathrm{~L}$. Moreover, the mass of the battery is less related to the gliding ratio. At the same condition, the gliding ratio for BWBUGII is higher than that for BWBUG-I. For steady gliding speed, Fig. 15 reveals that the gliding speed is affected by the buoyancy regulating capacity more than the mass of the battery pack. The gliding speed witness a linear growth with the buoyancy regulating capacity. At the same condition, steady gliding velocity for BWBUG-II is larger than that of BWBUG-I. By combining Fig. 14 and Fig. 15, the gliding ratio and steady gliding velocity are two contradictory characters in terms of the 
buoyancy regulating capacity. The BPRS with stronger buoyancy regulating capacity will lead to a smaller gliding ratio and a higher gliding speed. In other words, the gliding ratio need to be sacrificed to achieve a higher gliding speed and vice versa.

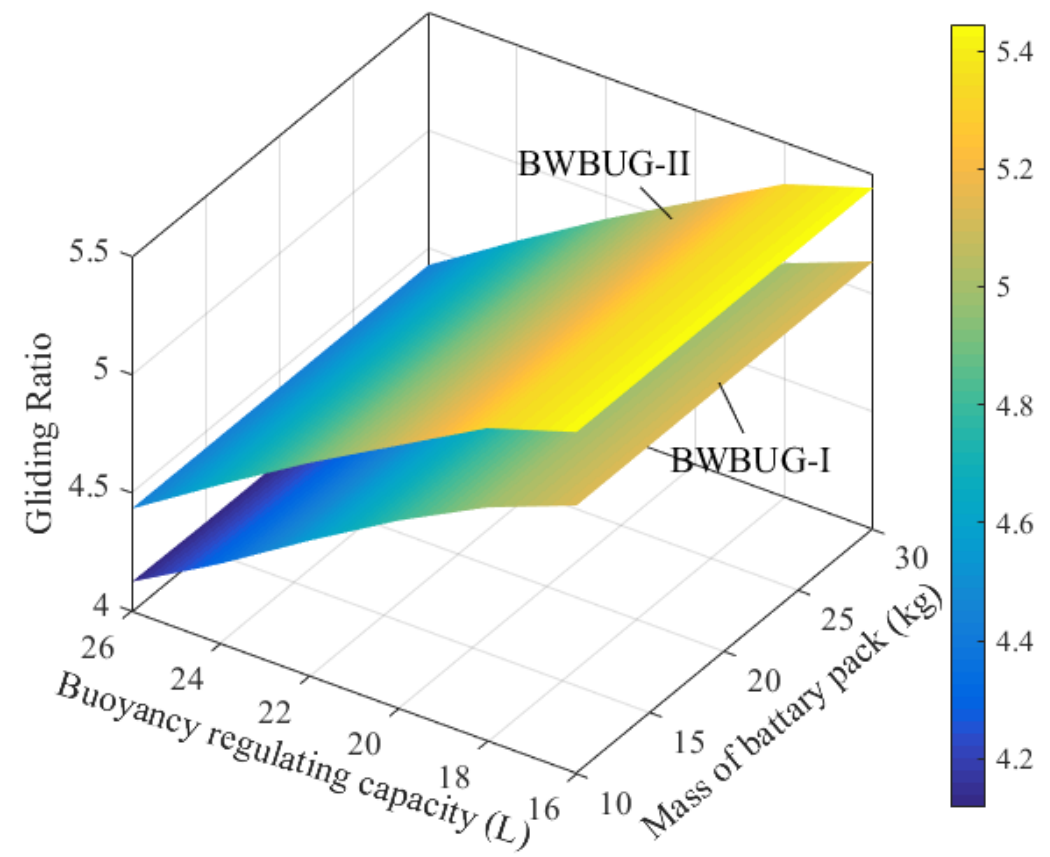

Fig. 14. Gliding ratio with buoyancy regulating capacity and mass of battery pack

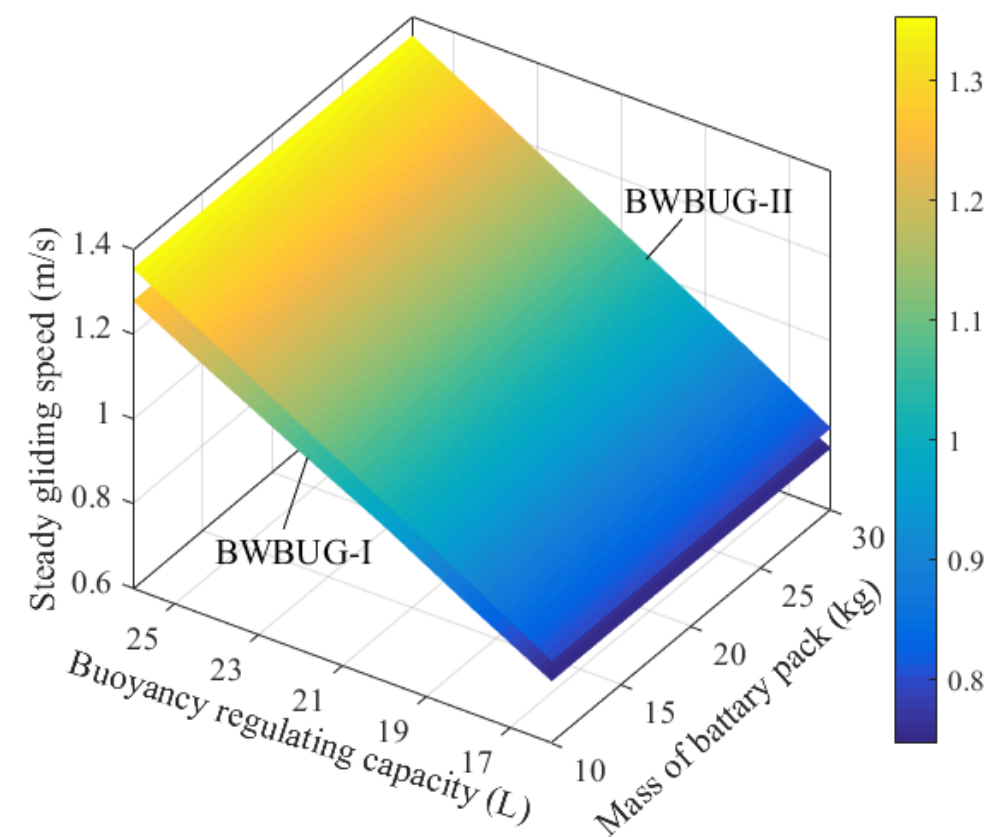

Fig. 15. Gliding velocity with buoyancy regulating capacity and mass of battery pack

As for the squat trajectory, the squat depth and horizontal displacement during regulating is studied when the buoyancy regulating capacity and mass of battery pack is fixed to $20 \mathrm{~L}$ and $20 \mathrm{~kg}$, respectively. Fig. 16 illustrate that the squat depth for BWBUG-I is larger than that BWBUG-II. For each underwater glider, the flow rate for buoyancy regulating system and moving speed of the battery pack both show an obvious impact on squat depth and the horizontal displacement. The squat 
depth reaches its bottom to $3.5 \mathrm{~m}$ when the flow rate and the moving speed of the battery pack are $30 \mathrm{~L} / \mathrm{min}\left(5 \times 10^{-4} \mathrm{~m}^{3} \cdot \mathrm{s}^{-1}\right)$ and $0.1 \mathrm{~m} / \mathrm{s}$ respectively. The horizon displacement reveals a same trend with squat depth, according to Fig. 17. In the meanwhile, the gap between two underwater gliders is smaller in horizontal depth than that in squat depth. Overall, an effective BPRS to change the attitude of BWBUG relies on a larger flow rate of buoyancy regulating system and a larger moving speed of the battery pack.

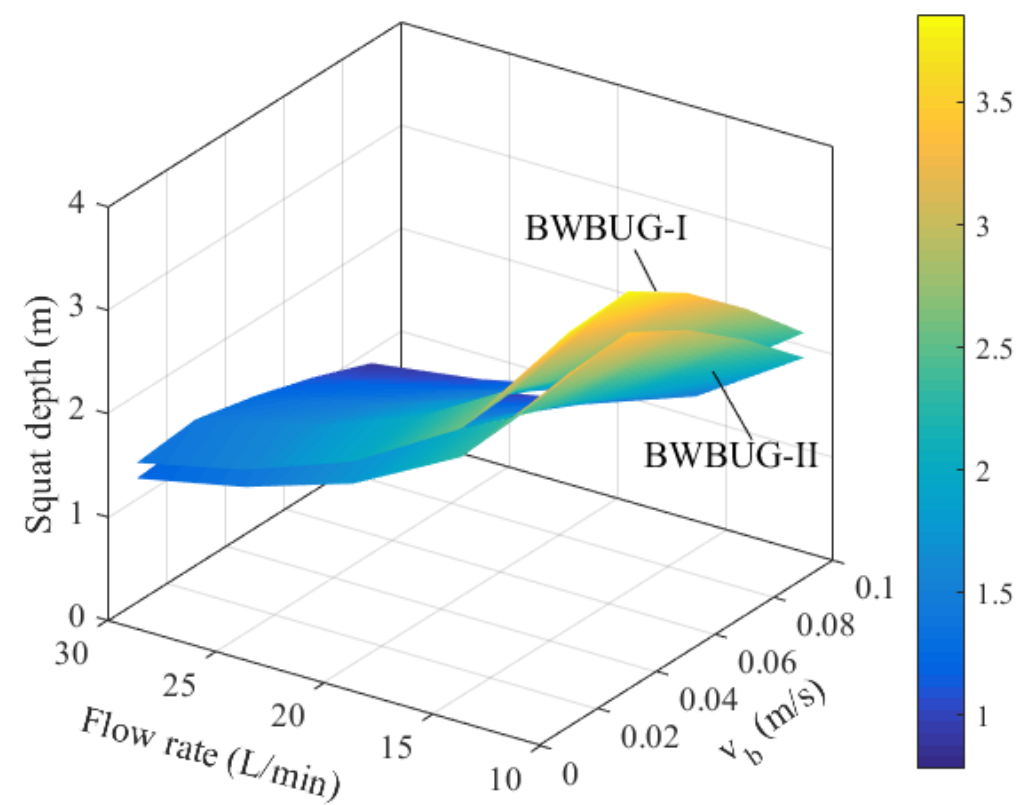

Fig. 16. Depth lower than the target gliding depth in DTRRP (squat depth) with flow rate of the buoyancy regulating system and speed of the battery pack $v_{b}$.

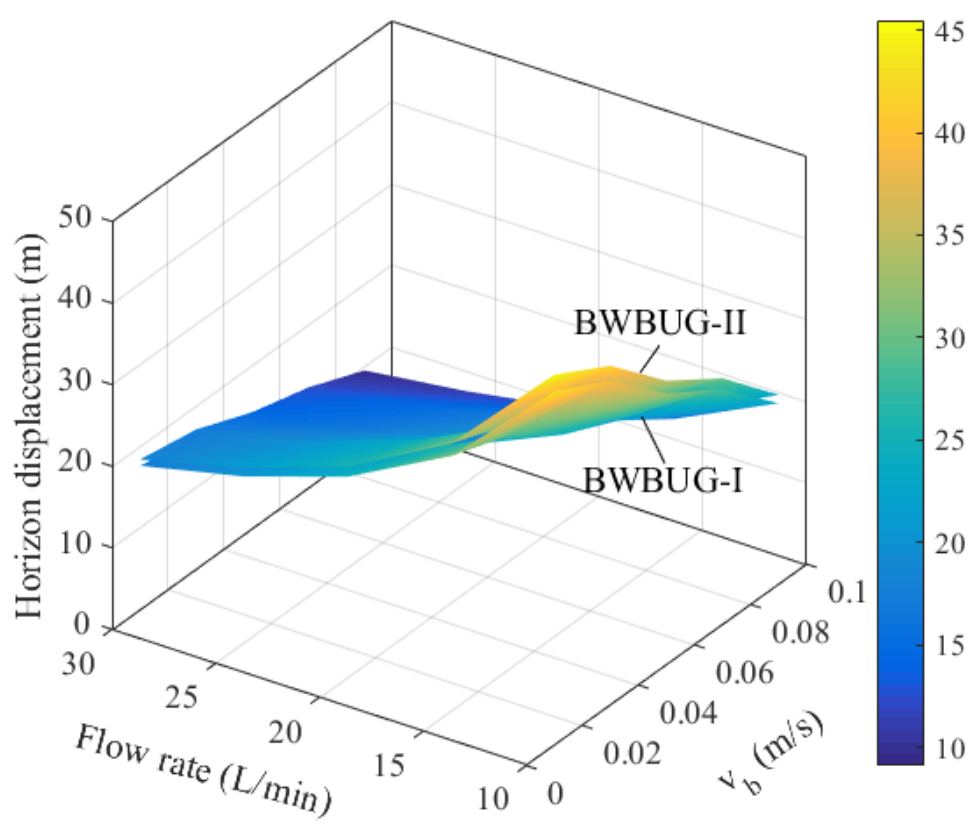

Fig. 17. Horizontal displacement in DTRRP with flow rate of the buoyancy regulating system and speed of the battery pack $v_{b}$.

\section{Conclusion}


In this paper, the hydrodynamic performance for two underwater gliders, BWBUG-I without winglet and BWBUG-II with winglet, are investigated and a dynamic model is established by considering the buoyancy and pitch regulating system (BPRS) inside the glider to calculate the profiling trajectory of two gliders. Comparison on hydrodynamic performance of the two gliders shows that the winglet helps to improve lift force within the characterized gliding speed range while the drag only experiences a relatively small increase. As a result, the lift-to-drag ratio is improved by the winglet. In terms of the hydrodynamic moment, the pitch moment is reduced by $31.6 \%$ and $28.3 \%$ when velocity is $0.5 \mathrm{~m} / \mathrm{s}$ and $1 \mathrm{~m} / \mathrm{s}$ respectively while the yaw moment is increased by $59.7 \%$ and $59.3 \%$ respectively at the same condition for BWBUG-II when compared with BWBUG-I.

The trajectory for BWBUG-I and BWBUG-II can be different including the gliding ratio, gliding speed, and the squat trajectory during the switch between diving and rising due to the effect of winglet and BPRS parameters.

The gliding ratio for BWBUG-II is larger than that of BWBUG-II regardless of ceiling depth during a gliding motion, demonstrating that the winglet helps to improve the gliding ratio. According to the simulated trajectory, by applying the winglet to BWBUG, the steady gliding ratio during the diving phase is improved by $2.5 \%$ from 5.05 to 5.18 while during the rising phase the gliding ratio is improved by $1.8 \%$ from 4.92 to 5.01 .Besides, for each underwater glider, the squat trajectory is not affected by the ceiling depth.

The buoyancy regulating capacity, rather than the mass of the battery pack, is the main factor to affect the gliding ratio for each BWBUG e.g. for BWBUG-II, the gliding ratio can be improved from 4.4 to 5.4 by decreasing the buoyancy regulating volume from $26 \mathrm{~L}$ to $16 \mathrm{~L}$. However, the decrease of buoyancy regulating volume will result in the steady gliding speed to decrease.

Comparison between the squat trajectories of BWBUG-I and BWBUG-II reveals that the improvement in hydrodynamic performance bring by winglet has also helps to reduce the extreme attack angle during the regulating procedure, which means the winglet also contribute to the safety of the BWBUG considering that a large attack angle may result in stall which should be avoided at any time. The squat trajectories of the underwater gliders are influenced by the flow rate of the buoyancy regulating system and the moving speed of the battery pack. The squat depth can be reduced from $3.8 \mathrm{~m}$ to $0.9 \mathrm{~m}$ for BWBUG-I when the flow ratio changes from $10 \mathrm{~L} / \mathrm{min}\left(1.67 \times 10^{-4}\right.$ $\left.\mathrm{m}^{3} \cdot \mathrm{s}^{-1}\right)$ to $30 \mathrm{~L} / \mathrm{min}\left(5 \times 10^{-4} \mathrm{~m}^{3} \cdot \mathrm{s}^{-1}\right)$ and the moving speed for battery pack changes from $0.01 \mathrm{~m} / \mathrm{s}$ to $0.1 \mathrm{~m} / \mathrm{s}$, when the buoyancy regulating volume is $20 \mathrm{~L}$ and the mass of battery pack is $20 \mathrm{~kg}$. For BWBUG-II with winglet, the squat depth can be reduced from $3.2 \mathrm{~m}$ to $0.7 \mathrm{~m}$ at the same condition.

The principal finding of this paper is that the winglet helps to improve the gliding ratio and the gliding speed for steady gliding, and reduce the extreme attack angle, squat depth during the regulating procedure. The squat trajectory is influenced by both winglet and regulating speed of BPRS.

\section{Acknowledgments}

This works is supported by the National Natural Science Foundation of China (Grant No. 11502210,51479170 and 51879220) and the National Key Research and Development Program of China (Grant No.2016YFC0301300). The financial support provided by China Scholarship Council (Grant No.201706290280) is also acknowledged.

\section{Appendix}


A. Design of structure and configuration of winglet used by BWBUG(Lü et al., 2018)

The winglet discussed in this paper is single upper blended winglet. This type of winglet is currently the most commonly applied type in aviation industry. In the previous published research, we investigated the drag reduction effect of different winglet on BWBUG. Three parameters to determine the configuration of winglet including height $h$, sweep angle $\eta$ and slope ratio $\gamma$ are considered and in total of 10 winglets configuration (W1 W10) is established and compared. The parameters are listed in Table 5 .
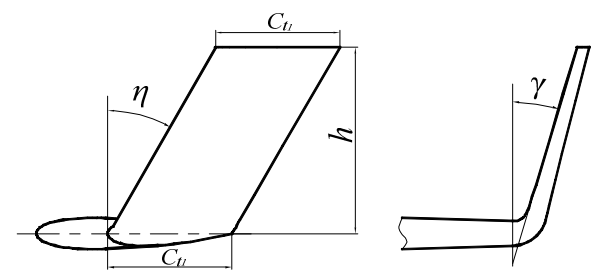

Fig. 18. Configuration of winglet with parameters including height $h$, sweep angle $\eta$ and slope ratio $\gamma$.

Table 5 Parameters of different winglet

\begin{tabular}{cccc}
\hline & $h(\%)$ & $\eta\left(^{\circ}\right)$ & $\gamma\left(^{\circ}\right)$ \\
\hline W1 & 5 & 0 & 0 \\
W2 & 10 & 0 & 0 \\
W3 & 15 & 0 & 0 \\
W4 & 20 & 0 & 0 \\
W5 & 10 & 15 & 0 \\
W6 & 10 & 30 & 0 \\
W7 & 10 & 45 & 0 \\
W8 & 10 & 30 & 15 \\
W9 & 10 & 30 & 30 \\
W10 & 10 & 30 & 45 \\
\hline
\end{tabular}

Then the numerical validation is finished before calculating the hydrodynamic performance in profiling plane of each configuration. The lift force, drag force and pitch moment are obtained. Comparison of nondimensional coefficient between the original BWBUG without winglet (BWBUG-I in this paper) and the BWBUG with different winglet shows that a proper winglet helps to reduce the drag, especially when the attack angle is larger than $6^{\circ}$. By observing the vortex in the wake flow, we found that a proper winglet can reduce the vortex magnitude and inhibit the occurrence of vortex. Among the configuration, W6 overall appears to have a great drag reduction effect under each attack angle, so we adopted the configuration of W6 in this paper as BWBUG-II. The drag reduction effect of positive attack angle and negative attack angle shows a slight difference, demonstrating that the asymmetrical character brings relatively small effect on the hydrodynamic performance of BWBUG in profiling plane. Fig. 19 illustrates that the upper-wash effect is inhibited by the winglet, which may be also the reason the winglet affects the hydrodynamic performance of BWBUG. 


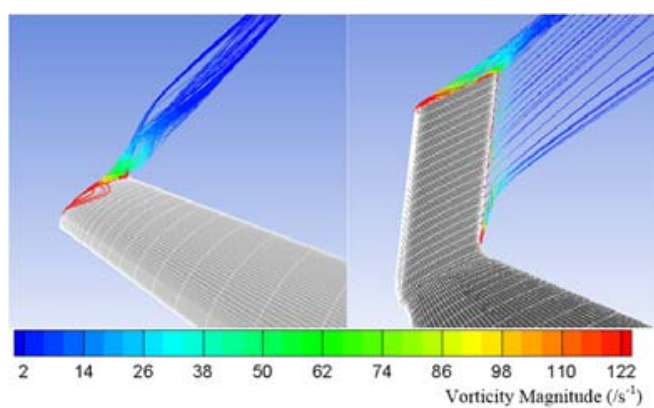

Fig. 19. Comparison of pathline colored by vorticity magnitude between BWBUG-I and BWBUG-II when attack angle is $6^{\circ}$.

\section{B. Detailed hydrodynamic parameter of BWBUG-I and BWBUG-II}

The hydrodynamic performance of a BWBUG can be divided into three parts, the positional hydrodynamic characters, rotational coupling characters and added mass characters.

In this paper, the positional hydrodynamic characters are calculated by straight-line simulation. The rotational coupling characters are calculated by rotating arm simulation. The added mass characters are obtained by using periodical acceleration simulation. All of the hydrodynamic characters are nondimensionallized. The detailed hydrodynamic parameter of BWBUG-I and BWBUG-II are listed in Table 6. The positional hydrodynamic coefficient and rotational coupling coefficient are affected by Reynolds number. However, we found that the nondimensional coefficient under two velocity, $0.5 \mathrm{~m} / \mathrm{s}$ and $1 \mathrm{~m} / \mathrm{s}$, has a relatively small difference. In this case, we only list the coefficient under $0.5 \mathrm{~m} / \mathrm{s}$.

Table 6 Physical characters and hydrodynamic characters of BWBUG-I and BWBUG-II

\begin{tabular}{|c|c|c|c|c|c|c|c|c|c|c|c|c|c|}
\hline & & \multicolumn{6}{|c|}{ BWBUG-I } & \multicolumn{6}{|c|}{ BWBUG-II } \\
\hline Volume & $V o\left(\mathrm{~m}^{3}\right)$ & \multicolumn{6}{|c|}{0.2255} & \multicolumn{6}{|c|}{0.2256} \\
\hline Average chord length & $L_{c}(\mathrm{~m})$ & \multicolumn{12}{|c|}{1.8} \\
\hline Mass & $m(\mathrm{~kg})$ & \multicolumn{6}{|c|}{225.5} & \multicolumn{6}{|c|}{225.6} \\
\hline Moment of inertia & $\left(J_{x}, J_{y}, J_{z}\right)\left(\mathrm{kg} \cdot \mathrm{m}^{2}\right)$ & \multicolumn{6}{|c|}{$(22.3,58.9,38.9)$} & \multicolumn{6}{|c|}{$(22.9,59.8,39.1)$} \\
\hline Reference area & $A\left(\mathrm{~m}^{2}\right)$ & \multicolumn{6}{|c|}{3.76} & \multicolumn{6}{|c|}{3.83} \\
\hline & $C_{x_{0}}\left(\times 10^{-3}\right)$ & \multicolumn{6}{|c|}{7.16} & \multicolumn{6}{|c|}{7.17} \\
\hline Positional hydrodynamic & $C_{y}^{\alpha}, m_{z}^{\alpha}$ & \multicolumn{6}{|c|}{$1.03,-0.026$} & \multicolumn{6}{|c|}{$1.15,-0.017$} \\
\hline coefficient & $C_{z}^{\beta}, m_{y}^{\beta}\left(\times 10^{-4}\right)$ & \multicolumn{6}{|c|}{$19,3.6$} & \multicolumn{6}{|c|}{$20,4.8$} \\
\hline & $C_{y}^{\bar{m}_{s}}, m_{x}^{\sigma_{x}}, m_{y}^{\bar{m}_{x}}, m_{z}^{\sigma_{x}}\left(\times 10^{-2}\right)$ & \multicolumn{6}{|c|}{$-1.42,-4.58,0.54,0$} & \multicolumn{6}{|c|}{$-1.31,-5.01,0.25,1.5$} \\
\hline Rotational coupling & $C_{y}^{\pi_{y}}, C_{z}^{\overline{\omega_{y}}}, m_{x}^{\bar{\pi}_{y}}, m_{y}^{\Phi_{y}}\left(\times 10^{-2}\right)$ & \multicolumn{6}{|c|}{$0,-5.87,0,-0.56$} & \multicolumn{6}{|c|}{$0.14,-6.53,-0.27,-0.93$} \\
\hline & $m_{x}^{\bar{s}_{s}}$ & \multicolumn{6}{|c|}{0.0568} & \multicolumn{6}{|c|}{0.0572} \\
\hline \multirow{6}{*}{ Added mass matrix } & \multirow{6}{*}{$I_{a}$} & {$[-24.7$} & 0 & 0 & 0 & 0 & 0 & $\lceil-24.6$ & 0.05 & 0 & 0 & 0 & $0.1]$ \\
\hline & & -4.9 & -645.8 & 0 & 0 & 0 & 155.3 & -6.4 & -650.4 & 0 & 0 & 0 & -159.7 \\
\hline & & -4.9 & 0 & -86.7 & 0 & 19.3 & 0 & -6.4 & 0.15 & -89.4 & -0.7 & -17.7 & -0.03 \\
\hline & & -4.9 & 0 & 0 & -90.1 & 0 & 0 & -7.7 & 0 & 0 & -92.5 & 0.51 & -0.58 \\
\hline & & -5.5 & 0 & 0 & 0 & -14.5 & 0 & -6.0 & 0.12 & -18.7 & 0.49 & -18.4 & 0 \\
\hline & & -4.8 & 150.2 & 0 & 0 & 0 & -101.6 & -6.2 & -160.1 & 0 & 0 & 0 & -100.0 \\
\hline
\end{tabular}

\section{Reference}

Ayuso Moreno, L.M., Sant Palma, R., Plagaro Pascual, L., 2006. Aerodynamic study of a blended wing body, comparison with a conventional transport airplane.

D’Spain, G.L., Jenkins, S.A., Zimmerman, R., Luby, J.C., Thode, A.M., 2005. Underwater acoustic measurements with the Liberdade/X-Ray flying wing glider. The Journal of the Acoustical Society of America 117 (4), 2624-2624.

Eichhorn, M., 2010. Solutions for practice-oriented requirements for optimal path planning for the AUV "Slocum Glider", OCEANS 2010 MTS/IEEE SEATTLE. IEEE, pp. 1-10.

Eleanor, F.W., Eriksen, C.C., Rhines, P.B., Harcourt, R.R., 2011. Determining vertical water velocities from Seaglider. Journal of Atmospheric and Oceanic Technology 28 (12), 1641-1656. 
Eriksen, C.C., Osse, T.J., Light, R.D., Wen, T., Lehman, T.W., Sabin, P.L., Ballard, J.W., Chiodi, A.M., 2001. Seaglider: A long-range autonomous underwater vehicle for oceanographic research. IEEE Journal of oceanic engineering 26 (4), 424-436.

Fan, S., Woolsey, C.A., 2014. Dynamics of underwater gliders in currents. Ocean Engineering 84, 249258.

Fu, X., Lei, L., Yang, G., Li, B., 2018. Multi-objective shape optimization of autonomous underwater glider based on fast elitist non-dominated sorting genetic algorithm. Ocean Engineering 157, 339-349.

He, Y., Song, B., Cao, Y., 2017. Structural optimization of an underwater glider with blended wing body. Advances in Mechanical Engineering 9 (9), 1687814017723279.

Klinck, H., Mellinger, D.K., Roch, M.A., Klinck, K., Bogue, N.M., Luby, J.C., Jump, W.A., Pyle, J.M., Shilling, G.B., Litchendorf, T., 2011. Passive-acoustic monitoring of odontocetes using a Seaglider: First results of a field test in Hawaiian waters. The Journal of the Acoustical Society of America 129 (4), 25362536.

Liebeck, R., Page, M., Rawdon, B., 1998. Blended-wing-body subsonic commercial transport, 36th AIAA Aerospace Sciences Meeting and Exhibit, p. 438.

Lü, D., Song, B., Jiang, J., Huang, Q., 2018. Research on drag reduction effect of winglet applied in blended-wing-body underwater gliders. Journal of Huazhong University of Science and Technology (Natural Science Edition) 46 (6), 65-70.

Riley, D.R., 1951. Wind-tunnel investigation and analysis of the effects of end plates on the aerodynamic characteristics of an unswept wing.

Rudnick, D., Davis, R., Ohman, M., Kessler, W., Owens, B., Chavez, F., Send, U., 2010. The underwater glider Spray: Observations around the world.

Sherman, J., Davis, R.E., Owens, W., Valdes, J., 2001. The autonomous underwater glider" Spray". IEEE Journal of oceanic engineering 26 (4), 437-446.

Sun, C., Song, B., Wang, P., 2015. Parametric geometric model and shape optimization of an underwater glider with blended-wing-body. International Journal of Naval Architecture and Ocean Engineering 7 (6), 995-1006.

Sun, C., Song, B., Wang, P., Wang, X., 2017. Shape optimization of blended-wing-body underwater glider by using gliding range as the optimization target. International Journal of Naval Architecture and Ocean Engineering 9 (6), 693-704.

Takenaka, K., Hatanaka, K., Yamazaki, W., Nakahashi, K., 2008. Multidisciplinary design exploration for a winglet. Journal of Aircraft 45 (5), 1601-1611.

Wang, S., Sun, X., Wang, Y., Wu, J., Wang, X., 2011. Dynamic modeling and motion simulation for a winged hybrid-driven underwater glider. China Ocean Engineering 25 (1), 97-112.

Wang, Z., Ye, L., Aobo, W., Xiaobing, W., 2015. Flying wing underwater glider: Design, analysis, and performance prediction, Control, Automation and Robotics (ICCAR), 2015 International Conference on. IEEE, pp. 74-77.

Webb, D.C., Simonetti, P.J., Jones, C.P., 2001. SLOCUM: An underwater glider propelled by environmental energy. IEEE Journal of oceanic engineering 26 (4), 447-452.

Weierman, J., Jacob, J., 2010. Winglet design and optimization for UAVs, 28th AIAA Applied Aerodynamics Conference, p. 4224.

Woithe, H.C., Chigirev, I., Aragon, D., Iqbal, M., Shames, Y., Glenn, S., Schofield, O., Seskar, I., Kremer, U., 2010. Slocum glider energy measurement and simulation infrastructure, OCEANS 2010 IEEESydney. IEEE, pp. 1-8. 
Yang, Y., Liu, Y., Wang, Y., Zhang, H., Zhang, L., 2017. Dynamic modeling and motion control strategy for deep-sea hybrid-driven underwater gliders considering hull deformation and seawater density variation. Ocean Engineering 143, 66-78.

Zarruk, G.A., Brandner, P.A., Pearce, B.W., Phillips, A.W., 2014. Experimental study of the steady fluidstructure interaction of flexible hydrofoils. Journal of Fluids and Structures 51, 326-343. 